\title{
Arbuscular Mycorrhizal Fungi Increase Crop Yields by Improving Biomass under Rainfed Condition: a meta-analysis
}

\author{
Shanwei Wu ${ }^{1,2,3}$, Zhaoyong Shi ${ }^{\text {Corresp., } 1,2,3}$, Xianni Chen ${ }^{1,2,3}$, Jiakai Gao ${ }^{1}$, Xugang Wang ${ }^{1}$ \\ ${ }^{1}$ College of Agriculture, Henan University of Science and Technology, Luoyang, Henan Province, China \\ 2 Henan Engineering Research Center of Human Settlements, Luoyang, Henan Province, China \\ 3 Luoyang Key Laboratory of Symbiotic Microorganism and Green Development, Luoyang, Henan Province, China \\ Corresponding Author: Zhaoyong Shi \\ Email address: 9903105@haust.edu.cn
}

B ackground. Rainfed agriculture plays key role in ensuring food security and maintain ecological balance. Especially in developing areas, most grain food are produced rainfed agricultural ecosystem. Therefore, the increase of crop yields in rainfed agricultural ecosystem becomes vital as well as ensuring global food security. Methods. The potential roles of arbuscular mycorrhizal fungi (AMF) in improving crop yields under rainfed condition were explored based on 546 pairs of observations published from 1950 to 2021. Results. AMF inoculation increased $23.0 \%$ crop yields based on 13 popular crops under rainfed condition. Not only was crop biomass of shoot and root increased $24.2 \%$ and $29.6 \%$ by AMF inocula, respectively but also seed number and pod/fruit number per plant were enhanced markedly. Further, the effect of AMF on crop yields depended on different crop groups. AMF improved more yield of $\mathrm{N}$-fixing crops than non-N-fixing crops. The effect of AMF changed between grain and non-grain crops with the effect size of 0.216 and 0.352 , respectively. AMF inoculation enhances stress resistance and photosynthesis of host crop in rainfed agriculture. Conclusion. AMF increased crop yields by enhancing shoot biomass due to the improvement of plant nutrition, photosynthesis, and stress resistance in rainfed field. Our findings provide a new view for understanding the sustainable productivity in rainfed agroecosystem, which enriched the theory of AMF functional diversity. This study provided a theoretical and technical way for sustainable production under rainfed agriculture. 
1 Arbuscular Mycorrhizal Fungi Increase Crop Yields by 2 Improving Biomass under Rainfed Condition: a meta3 analysis

5 Shanwei $\mathrm{Wu}^{1,2,3}$, Zhaoyong Shi ${ }^{1,2,3, *}$, Xianni Chen ${ }^{1,2,3}$, Jiakai Gao ${ }^{1}$ and Xugang Wang ${ }^{1}$ 6

$7 \quad{ }^{1}$ College of Agriculture, Henan University of Science and Technology, Luoyang, 471023, Henan

8 Province, China;

$9 \quad{ }^{2}$ Luoyang Key Laboratory of Symbiotic Microorganism and Green Development, Luoyang,

10 471023, Henan Province, China;

$11{ }^{3}$ Henan Engineering Research Center of Human Settlements, Luoyang, 471023, Henan Province, 12 China;

$13 *$ Corresponding Author 14

15 Corresponding Author:

16 Zhaoyong Shi

17 263\# Kaiyuan Road, Luoyang, Henan Province, 471023 P.R China

18 Email address: shizy1116@126.com

19 


\section{Abstract}

21 Background. Rainfed agriculture plays key role in ensuring food security and maintain

22 ecological balance. Especially in developing areas, most grain food are produced rainfed

23

24

25

26

27

28

29

30

31

32 agricultural ecosystem. Therefore, the increase of crop yields in rainfed agricultural ecosystem becomes vital as well as ensuring global food security.

Methods. The potential roles of arbuscular mycorrhizal fungi (AMF) in improving crop yields under rainfed condition were explored based on 546 pairs of observations published from 1950 to 2021 .

Results. AMF inoculation increased $23.0 \%$ crop yields based on 13 popular crops under rainfed condition. Not only was crop biomass of shoot and root increased $24.2 \%$ and $29.6 \%$ by AMF inocula, respectively but also seed number and pod/fruit number per plant were enhanced markedly. Further, the effect of AMF on crop yields depended on different crop groups. AMF improved more yield of $\mathrm{N}$-fixing crops than non-N-fixing crops. The effect of AMF changed between grain and non-grain crops with the effect size of 0.216 and 0.352 , respectively. AMF inoculation enhances stress resistance and photosynthesis of host crop in rainfed agriculture.

Conclusion. AMF increased crop yields by enhancing shoot biomass due to the improvement of plant nutrition, photosynthesis, and stress resistance in rainfed field. Our findings provide a new view for understanding the sustainable productivity in rainfed agroecosystem, which enriched the theory of AMF functional diversity. This study provided a theoretical and technical way for sustainable production under rainfed agriculture.

Subjects Agriculture, Agriculture Science, Mycology, Soil Science

Keywords Arbuscular mycorrhizal fungi, Rainfed agriculture, Crop yields, Functional groups, Meta-analysis

\section{Introduction}

Rainfed agriculture is a farming type that relies on rainfall, which plays a dominant role in producing food for increasing world population (Molle, 2008). Rainfed areas cover worldwide $80 \%$ of the cultivated land, and contribute about $60 \%$ of crop production (UNESCO, 2009). The rainfed farmland get to more than $95 \%$ of the total cultivated area in sub-Saharan Africa, $90 \%$ in Latin America, 75\% in the Near East and North Africa, 65\% in East Asia, and 60\% in South Asia (Giordano et al., 2012), which ensures food security for mankind, especially in some 
50 developing countries (Rosegrant et al., 2002). With the more and more serious global warming 51 (Birara et al., 2018; Yadav et al., 2018), the global food security also has been threatened by the impact of climate on crop productivity (van der Linden \& Goldberg, 2020). Ahmed and Hassan (2015) confirmed that the climate change affected adversely crop yield in rainfed area. Rainfall and temperature are recognized as the two most important factors during climate changes (Abera et al., 2018; Gebrechorkos et al., 2019), which also influence the plant growth in rainfed cropland (Gebrechorkos et al., 2019). In subhumid and humid zones, rainfed agriculture generates high yields because of relatively reliable rainfall and inherently productive soils (Molden et al., 2011). However, arid and semiarid regions have experienced the low yield, which is a problem to be solved. Licker et al. (2010) estimated that winter wheat produced only $25 \%$ to $50 \%$ potential yields under non-irrigated condition comparing to irrigated field in global rainfed agriculture. Jin et al (2016) also indicated that the wheat yield is 2.3 times higher in irrigated farmland than that in rainfed condition in Loess Plateau of China. On one hand, water stress may lead to stomata closure, which inhibits nutrient uptake (DOWNTON et al., 1988). On the other hand, water stress induces plant nutrient uptake and water use efficiency due to the decrease of microbial activity in soil (Yi et al., 2007; Wang et al., 2017). A lot of studies have testified that crop nutrition was also limited under rainfed condition in developing countries (Salvagiotti et al., 2008; Setiyono et al., 2010; Qin et al., 2015). Therefore, nutrient and water uptake were two vital factors for increasing crop yield in rainfed region (Xu et al., 2021). Besides, there are also several factors which lead to the reduction of crop productivity under rainfed condition, such as land degradation, nutrient depletion and biodiversity decrease.

It is important not only to increase the yield in rainfed area but also to protect soil biodiversity by taking sustainable management practices. Many management measures have been employed to enhance crop yield with the aim to ameliorate abiotic stress, such as soil mulching management (Gan et al., 2013), different tillage system (Bakhshandeh et al., 2017) and biological fertilizer application (Karaca et al., 2013; Cavagnaro et al., 2015). Among of them, arbuscular mycorrhizal fungal inoculation has been concentrated widely due to its functions in improving the water status of host plant in agroecosystem (Bryla \& Duniway, 1997; Askari et al., 2019). Hijri (2016) clearly demonstrated the advantage of arbuscular mycorrhizal fungal inoculation on potato yield in large-scale production system. As a natural bio-fertilizer, Arbuscular mycorrhizal fungi (AMF) are paid special attraction owing to their important roles in 
81 improving nutrition of host plants and status of soil fertility (Karaca et al., 2013). AMF

82 inoculation can improve plant growth through increasing nutrients absorption, photosynthesis

83 (Ruiz-Sánchez et al., 2010) and water stress resistance (Heidari \& Karami, 2014). Meanwhile,

84 AMF inoculum is also an environment-friendly agronomic measure to enhance crop yield

85 (Celebi et al., 2010), which is considered as a promising option in ensuring crop yield and food

86

87

88

89

90

91

92

93

94

95

96

97

98

99

100

101

102

103

104

105

106

107

108

109

110

111

security in rainfed agriculture (Rillig et al., 2016; Thirkell et al., 2017). Numerous studies have reported that AMF was able to improve the absorption of nutrients such as phosphorus, nitrogen, and zinc in plants (Ardakani et al., 2009). Smith and Read (2008) pointed out that AMF inoculation can supply up to $90 \%$ of plant $\mathrm{P}$ and $20 \%$ of plant $\mathrm{N}$ due to the hyphal networks in the soil formed symbiotic associations with host plant, which is also confirmed in Johnson's finding (2012). In particular, the impacts of abiotic stress such as drought, nutrient imbalance and temperature regimes on plant growth finally have decreased crop yield up to $70 \%$ (Saxena et al., 2013; Kumar et al., 2020). The resistances of plant which inoculated with AMF were enhanced by improving tissue hydration and stomatal conductance (Augé et al., 2015) and photosynthesis (Quiroga et al., 2017; Amirnia et al., 2019) and alleviating oxidative stress (Chitarra et al., 2016; Mirshad \& Puthur, 2016). Especially under water stress, AMF can improve water status of host plant and maintain osmotic balance (Ruiz-Lozano, 2003; Porcel et al., 2006; Malfanova et al., 2011; Bárzana et al., 2014; Li et al., 2016). Wu and Xia (2006) also drew a conclusion that AMF played a key role in improving crop yield in rainfed agricultural system by improving drought resistance of host plants. Additionally, the influence of biotic stress also leaded to yield losses such as bacterial, viral, nematode phytopathogens and herbivores (Dowarah et al., 2021). AMF protects host plants against different biotic stresses by acting alone or in synergy with other native microorganisms (Dowarah et al., 2021). Many researches also pointed out that AMF stimulates plant growth and yield through increase the tolerance to biotic stress (Fiorilli et al., 2018; Bernaola \& Stout, 2020).

To evaluate the importance of AMF for crop yield under rainfed condition, we need a profound quantitative understanding. The mechanism that AMF can increase the crop yield under rainfed agriculture has been testified in some crops including wheat (Zhu et al., 2017), barley (Espidkar et al., 2017), soybean (Suri \& Choudhary, 2013), and chickpea (Erman et al., 2011; Sharma et al., 2019; Rezaie et al., 2020). However, the quantitative estimation of predictor variables on crop responses to inoculation with AMF in rainfed agriculture is scarce on a global 
112 scale. Meanwhile, in our knowledge, only two quantitative synthesis has so far targeted the AMF 113 effects on wheat (Pellegrino et al., 2015) and cereal crops (Zhang et al., 2019) in field studies.

114 For rainfed agriculture, there is no meta-analysis about AMF on crop yield and we are going to

115 fill this knowledge gap. Therefore, we hypothesize that: (1) AMF inoculation can increase the 116 crop yield in rainfed area; (2) AMF inoculation can enhance biomass in rainfed area. In this 117 study, we verified these hypotheses based on global data.

\section{Materials \& Methods}

\section{Establishment of database}

120 This study followed the PRISMA guidelines (Moher et al., 2016) (Figure 1). The published 121 papers from 1950 to 2021 in the Web of Science ${ }^{\mathrm{TM}}$ (subscripted by Henan University of Science 122 and Technology) have been searched. The Web of Science ${ }^{\mathrm{TM}}$ included multiple databases (Web 123 of Science Core Collection, MEDLINE, SciELO Citation Index, KCl-Korean Journal Database 124 and Russian Science Citation Index). The references cited in publications have also been 125 retrieved. Two researchers (Shanwei Wu and Xianni Chen) independently performed the search 126 strategy (Supplementary information Note S) following the methods in Foo et al (2021). All 127 discrepancies were resolved through discussion with each other or consultation with a 3rd 128 reviewer (Zhaoyong Shi). Our search terms were 'rain*fed OR non-irrigat* AND mycorrhiza*'. 129 These searches resulted in 72 articles. To ensure representativeness and accuracy of the results, 130 the following criteria were used to screen article for inclusion: (1) the articles had to be original 131 research, (2) field studies under rainfed conditions, (3) involve an AMF treatment and a corresponding control and (4) contained replicated controlled trials. Based on the above criteria, 21 articles were selected. The information of yield, biomass, replications and other variables including plant, nutrition and physiological characteristics were extracted from the article we selected. The digitizing software (GetData Graph Digitizer v.2.20) were used for data extraction if the data were only available via graphs.

137 For a more detailed investigation, five groups of moderator variables related to yield were used as explanatory variables in meta-analyses following the methods in Hoeksema (2010) and Zhang (2019). We focus on the most studied crops in rainfed area including wheat, soybean, barley, chickpea, lentil, sorghum, yellow sweet clover, strawberry, tomato, olive trees, lavender, rosemary and thyme. 
142 Crop Species had two levels with grain crops and non-grain crops. Chickpea (Cicer arietinum 143 L.), lentil (Lens culinaris Medik), wheat (Triticum aestivum L.), barley (Hordeum vulgare L.), 144 soybean (Glycine max L. Merrill) and sorghum (Sorghum bicolor) were grouped in grain crops. 145 Yellow sweet clover (Melilotus officinalis L.), strawberry (Fragariax ananassa), tomato 146 (Solanum lycopersicum), olive trees (Canarium spp.), lavender (Lavandula officinalis L.), 147 rosemary (Rosmarinus officinalis L.) and thyme (Thymus vulgaris) were grouped in non-grain 148 groups.

149 Crop Functional Group had two levels: N-fixing crops and non-N-fixing. Chickpea, lentil, 150 soybean and yellow sweet clover were grouped into N-fixing crops. Wheat, barley, sorghum, 151 strawberry, tomato, olive tree, lavender, rosemary and thyme were grouped into non-N-fixing 152 crops.

153 Crop yield component analysis is a general methodology aiming to probe in the yield-building 154 factors. The effect size of seed number per plant, pod/fruit number per plant, seed number per 155 spike, thousand seed weight and harvest index were calculated.

156 Biomass were grouped into shoot and root biomass.

157 Plant nutrients are not only the important indicators for plant growth and yield but also the best 158 available approach to assess the mycorrhizal function. The resulting effect sizes of plant (shoot, 159 leaf) nitrogen, phosphorus concentration (\% of biomass) represented the AMF effect on nutrient 160 status of plant tissues. The food qualities were indicated by the effect size of seed nitrogen, 161 phosphorus concentration and uptake.

162 Plant physiological characteristics included proline and chlorophyll. Crop yield is dependent 163 upon photosynthesis and the exchange of carbon metabolites from source to sink tissues (Giroux, 2019). As an important indicator of the growth and photosynthesis of plant (Sun et al., 2021), the leaf chlorophyll effect size were calculated. Additionally, the resistance of plant is an important indicator to plant growth under rainfed condition. Proline accumulation is responsible for plant resistance (Sharma \& Singh, 2016), which used as a biochemical marker of abiotic stress in plants. Therefore, proline and chlorophyll content were contained as two vital indicators of plant stress tolerance and photosynthesis.

170 To deal with non-independence issue, four types of corrections were conducted as applied 171 in previous publications: (1) For the effect of AMF on different plant species, one plant species 172 during different years or different AMF species in the same article, the observations were 
173 considered to be independent (Koide, 2003), (2) For multiple studies from one author/lab, the

174 observations were considered to be independent (Koide, 2003), (3) For the observations in the

175 same article with different treatment, we use the two-way method followed by song et al. (2021)

176 to handle non-independence issue, (4) For studies presenting multiple observations in the same

177 year, the observations were combined into one effect size value following a random-effects

178 meta-analysis model (Schütz et al., 2018). Finally, we assembled the Global Dataset of

179 Arbuscular Mycorrhizal Fungi and Crop Yields under Rainfed Agroecosystem in the

180 Supplementary Data Sheets. The locations of studies from database were shown in Figure 2.

181

182

Figure 1. Preferred Reporting Items for Systematic Reviews and Meta-analysis (PRISMA) flow diagram.

183

${ }^{1}$ We used the terms rain*fed or non-irrigat* and mycorrhiz*

184

${ }^{2}$ Web of science include 5 databases (Web of Science Core Collection, MEDLINE, SciELO Citation Index, KCl-

185

Korean Journal Database and Russian Science Citation Index)

186

${ }^{3}$ We used the following inclusion criteria: (1) the articles had to be original research, (2) field studies under rainfed

187 conditions, (3) involve an AMF treatment and a corresponding control and (4) contained replicated controlled trials.

188

189

Figure 2. The locations of studies included in the Global Dataset of Arbuscular Mycorrhizal Fungi and Crop Yields under Rainfed Agroecosystem.

The black triangle represents the locations of studies.

192

\section{Calculation of effect sizes}

194 The natural $\log$ response ratio $(\ln \mathrm{R})$ was used as effect size in our analyses to represent the AMF 195 effect on yield. The effect size was calculated followed the following equation:

$196 \mathrm{Ln} R=\ln \left(\mathrm{X}_{\mathrm{i}} / \mathrm{X}_{\mathrm{n}}\right)$, with $\mathrm{X}_{\mathrm{i}}$ denoting the yield in an inoculated treatment and $\mathrm{X}_{\mathrm{n}}$ indicating the 197 yield of the corresponding control. A positive ln R indicated a beneficial AMF effect on yield, 198 while negative values represented a negative effect. The effect size of AMF on yield component, 199 biomass, nutrition, harvest index, chlorophyll, and proline were calculated in the same way.

200 The effect size of AMF was calculated by the overall weighted mean effect size according 201 to the method described by Hoeksema et al. (2010) owing to the insufficient standard deviation 202 (SD) or standard errors (SE). The weighted value of effect size was estimated according the 203 method employed by Hoeksema et al. (2010). The detail procedure including: (1) the reciprocal 204 of the sum between AMF treatment replications and non-inoculated control replications (Rs) was 205 calculated, (2) the maximum likelihood was estimated, (3) the weight of effect size was obtained 
206 by adding Rs and maximum likelihood. All the analyses were conducted in R v.3.4.1 (R Core 207 Team, 2017) with 'METAFOR' package (Viechtbauer, 2010). The overall effect of AMF on 208 crop yields and other variables was estimated with the rma.uni() function by a random effect 209 model with a restricted maximum likelihood method.

210 To verify our analysis outcomes, sensitivity analysis was performed by using publication 211 bias (Supplementary information Figure S) (Sterne \& Egger, 2001) and there were no patterns 212 suggesting the existence of publication bias.

\section{Structural equation modeling}

214 Structural equation modeling (SEM) is a statistical method to express the relationship between 215 observation variables by using linear equation system. The advantage of SEM is estimate 216 interdependence of several variables. SEM was used in this study to evaluate the relationships 217 among AMF, biomass and yield. Simultaneously, the effects of nutrient, physiological 218 characteristics, environmental resistance, crop yield component, biomass, and yield were 219 analyzed. The standardized path coefficients (r) was calculated in R v.3.4.1 (R Core Team, 2017) 220 with 'Iavaan' package according to the method described by Jiang et al (2019) and Rosseel 221 (2012).

\section{Results}

\section{Effect of AMF on crop yields}

224 The crop yield increases $23.0 \%(\mathrm{CI}=16 \%-30 \%)$ by $\mathrm{AMF}$ inoculation in rainfed agriculture 225 (Figure 3a). To evaluate the function of AMF in different plant groups, grain crops and non-grain 226 crops were differentiated. The results showed that both grain crops and non-grain crops yielded 227 increase (Figure 3a). For the distribution of every effect size of yield, the effect size changed 228 from $-8 \%$ to $85 \%$ with the $76.2 \%$ positive effect sizes (Figure $3 \mathrm{~b}$ ). For grain crops, the positive, 229 neutral and negative effect size respectively accounted for 75.8\%, 23.1\% and 1.1\% (Figure 3c). 230 Due to the small sample size of non-grain crops, the effect size of yield only included positive $231(57.1 \%)$ and neutral (42.9\%) (Figure 3d).

Figure 3. Effect of arbuscular mycorrhizal fungi (AMF) on crop yields under rainfed condition. (a) Overall effect on crop yield in all, grain crops and non-grain crops. Effects are displayed as weighted means and 95\% Cis. 
237 (b) all (CI=16\%-30\%), (c) grain crops (CI=14\%-29\%) and (d) non-grain crops (CI=10\%-60\%). The vermilion, blue 238 and yellow data point represent the positive, neutral and negative effect.

239

240

241

242

243

244

245

246

247

248

249

250

251

252

253

254

255

256

257

258

259

260

261

262

263

264

265

266

267

268

269

When crops were classified into $\mathrm{N}$-fixing crops and non-N-fixing crops, the results showed that both $\mathrm{N}$-fixing and non- $\mathrm{N}$-fixing crops yielded positive but $\mathrm{N}$-fixing crops $(29.4 \%$, increase, $\mathrm{CI}=16 \%-43 \%)$ was higher than non-N-fixing crops (20.4\%, increase, $\mathrm{CI}=12 \%-28 \%)$ (Figure 4). Among $\mathrm{N}$-fixing crops and non-N-fixing crops, as the widely farmed and studied crops in rainfed area, chickpea and wheat were increased by $18.1 \%(\mathrm{CI}=1 \%-35 \%)$ and $34.1 \%(\mathrm{CI}=18 \%-51 \%)$, respectively (Figure 4).

Figure 4. Effect of arbuscular mycorrhizal fungi (AMF) on crop yields under rainfed condition for crop functional group (N-fixing crops and non-N-fixing crops). Effects are displayed as weighted means and 95\% Cis. ' $n$ ' represents trial numbers and ' $L$ ' represents literature numbers. The vermilion square and blue triangle represent the original data distribution of $\mathrm{N}$-fixing crops and non-N-fixing crops.

The results in figure 5 showed that the AMF inoculation significantly increased the seed number per plant and pod/fruit number per plant under rainfed condition. But the effect size of seed number per spike and thousand seed weight were neutral. Compared with non-inoculated AMF, the seed number per plant and pod/fruit number per plant increased by $32.2 \%(\mathrm{CI}=11 \%$ $54 \%)$ and $20.8 \%(\mathrm{CI}=1 \%-41 \%)$ by inoculating with $\mathrm{AMF}$.

Figure 5. Impact of arbuscular mycorrhizal fungi (AMF) on crop yield component under rainfed condition (seed number per plant, pod/fruit number per plant, seed number per spike and thousand seed weight). Effects are displayed as weighted means and $95 \%$ Cis. ' $n$ ' represents trial numbers and ' $L$ ' represents literature numbers. The vermilion square, blue triangle, yellow point and reddish purple diamond represent the original data distribution of seed number per plant, pod/fruit number per plant, seed number per spike and thousand seed weight.

\section{The effect size of AMF on biomass}

The effect of AMF on biomass depended on the organs (shoot and root) and functional groups of host plants (Figure 6a). Overall, the shoot and root biomass increased 24.2\% (CI=15\%-33\%) and $29.6 \%$ ( $\mathrm{CI}=16 \%-43 \%)$, respectively. The shoot biomass effect sizes of AMF were difference when crops were classified into grain and non-grain groups. The shoot biomass of non-grain crops increased with $54.9 \%$ ( $\mathrm{CI}=33 \%-77 \%)$ while grain crops with the enhancement of $17.4 \%$ 
$270(\mathrm{CI}=9 \%-26 \%)$. All the effect size in Figure $6 \mathrm{~b}$ and $6 \mathrm{c}$ showed that the positive effect size

271 accounted for 89.2 percent of the whole shoot biomass effect and 86.7 percent of the root

272 biomass.

273

274

Figure 6. Effect of arbuscular mycorrhizal fungi (AMF) on shoot and root biomass under rainfed condition.

275 (a) Overall effect on biomass in all, grain crops and non-grain crops shoot biomass and all root biomass. Effects are 276 displayed as weighted means and 95\% Cis. ' $n$ ' represents trial numbers and ' $L$ ' represents literature numbers. The

277 vermilion square, blue triangle and yellow point represent the original data distribution of all, grain crops and non278 grain crops in shoot biomass. The reddish purple diamond represent the original data distribution of root biomass.

279 (b-c) Effect size for each trial in (b) shoot biomass (CI=15\%-33\%), (c) root biomass (CI=16\%-43\%). The vermilion 280 and blue data point represent the positive and neutral effect.

281

282

When the plant functional groups were considered, both $\mathrm{N}$-fixing crops and non-N-fixing

283 crops exhibited positive response to shoot biomass by AMF inoculation under rainfed condition

284

285

286

287

288

289

290

291

292

293

294

295

296

297

298

299

300

301

302

(Figure 7). The shoot biomass of N-fixing crops was increased by $31.0 \%(\mathrm{CI}=18 \%-44 \%)$ which is higher than non-N-fixing crops ( $16.9 \%$, increase, $\mathrm{CI}=5 \%-28 \%)$. Among $\mathrm{N}$-fixing group, shoot biomass of dominated plant species yellow sweet clover and chickpea were increased $69.9 \%$ $(\mathrm{CI}=46 \%-95 \%)$ and $20.8 \%(\mathrm{CI}=7 \%-35 \%)$ by AMF in this study (Figure 7$)$. There was also different between $\mathrm{N}$-fixing crops and non-N-fixing crops in root biomass (Figure 7). The root biomass effect size of $\mathrm{N}$-fixing crops was neutral while the non-N-crops was positive $(29.6 \%$, increase, $\mathrm{CI}=15 \%-44 \%)$.

Figure 7. Effect of arbuscular mycorrhizal fungi (AMF) on shoot and root biomass between $\mathrm{N}$-fixing and non$\mathbf{N}$-fixing crops under rainfed condition. Effects are displayed as weighted means and $95 \%$ Cis. ' $n$ ' represents trial numbers and ' $L$ ' represents literature numbers. The vermilion square and blue triangle represent the shoot biomass original data distribution of $\mathrm{N}$-fixing crops and non-N-fixing crops. The yellow point and reddish purple diamond represent the root biomass original data distribution of $\mathrm{N}$-fixing crops and non- $\mathrm{N}$-fixing crops.

\section{The effect size of AMF on physiological status}

AMF inoculation apparently improved physiological status of host plant (Figure 8-10). In rainfed agriculture, the proline content was decreased more than $67.1 \%$ (CI=-92\%--43\%) by inoculated AMF. However, AMF inoculation increased $40.6 \%(\mathrm{CI}=11 \%-70 \%)$ in chlorophyll content of host plant under rainfed condition (Figure 8). 
303

304

305

306

307

308

309

310

311

312

313

314

315

316

317

318

319

320

321

322

323

324

325

326

327

328

329

330

331

332

333

334

335

336

The $\mathrm{N}$ and $\mathrm{P}$ in shoot were increased significantly by AMF (Figure 9) when the $\mathrm{N}$ and $\mathrm{P}$ concentration in shoot and leaf were estimated. The effect of AMF on shoot and leaf nutrition presented difference with the positive and neutral, respectively. The shoot $\mathrm{P}$ concentration increased by $46.0 \%(\mathrm{CI}=26 \%-66 \%)$, which is higher than shoot $\mathrm{N}$ concentration $(31.9 \%$, increase, $\mathrm{CI}=9 \%-55 \%)$. The neutral effect of AMF was observed in concentration of leaf $\mathrm{P}$ and $\mathrm{N}$ with $12.7 \%(\mathrm{CI}=-11 \%-37 \%)$ and $15.4 \%(\mathrm{CI}=-11 \%-42 \%)$. Moreover, there was a large different between nutrition concentrations of shoot and seed by AMF inoculation. The effect size of seed $\mathrm{P}$ and $\mathrm{N}$ uptake and concentration were neutral (Figure 10).

\section{Figure 8. Effect of arbuscular mycorrhizal fungi (AMF) on plant proline and chlorophyll under rainfed} condition. Effects are displayed as weighted means and $95 \% \mathrm{Cis}$. ' $\mathrm{n}$ ' represents trial numbers and ' $\mathrm{L}$ ' represents literature numbers. The vermilion square and blue triangle represent the original data distribution of proline and chlorophyll.

Figure 9. Effect of arbuscular mycorrhizal fungi (AMF) on nutrient concentration of shoot and leaf under rainfed condition. Effects are displayed as weighted means and 95\% Cis. ' $n$ ' represents trial numbers and ' $L$ ' represents literature numbers. The vermilion square and blue triangle represent the original data distribution of nitrogen and phosphorus concentration of shoot and leaf.

Figure 10. Effect of arbuscular mycorrhizal fungal (AMF) on nutrient concentration and uptake in seed under rainfed condition. Effects are displayed as weighted means and 95\% Cis. ' $n$ ' represents trial numbers and ' $L$ ' represents literature numbers. The vermilion square represents the original data distribution of phosphorus concentration and uptake of seed, the blue triangle represents the original data distribution of nitrogen concentration and uptake of seed.

\section{Relationships among AMF, physiological and yield}

Structural equation model analysis indicated that AMF had a positive effect on yield via its neutral effect on harvest index and positive effect on pod/fruit number, whereas AMF had positive effect on biomass via its influence on nutrition, chlorophyll, and abiotic resistance of the host plant. The direct positive effect of nutrition on biomass in response to AMF inoculation $(\mathrm{r}=0.18)$ was weaker than the direct positive effect of chlorophyll on biomass $(\mathrm{r}=0.99)$, whereas the direct effect of proline on biomass was negative $(\mathrm{r}=-0.98)$.

Biomass had a direct positive effect on yield $(\mathrm{r}=0.72)$, while the direct positive effect of pod/fruit number and harvest index on yield was not significant. The results also showed that the 
337 direct positive effect of biomass on pod/fruit number and harvest index was not significant 338 (Figure 11).

339

Figure 11. Structural equation model (SEM) analysis of relationships among AMF, response ratio of physiological characteristics (i.e., nutrition, chlorophyll and proline), biomass, yield component (i.e., pod/fruit number and harvest index) and yield. Black solid arrows represent significant positive or negative effects. Black dashed arrows represent nonsignificant paths. Number near lines represent standardized path coefficients (r), *** means $\mathrm{P}<0.001 ;$ ** means $\mathrm{P}<0.01$; * means $\mathrm{P}<0.05$, respectively.

345

346

\section{Discussion}

347

In this study, we explored firstly the AMF effect on crop yields in rainfed agricultural ecosystem.

Our results provide insight on how AMF effects on crop yield under rainfed condition and inform management practices in rainfed agriculture. However, there are limitations in this study. Some literatures may be missed because the word of rainfed was employed although studies were carried out under rainfed condition. The results showed that AMF increased $23.0 \%$ crop yield under rainfed condition (Figure 3a), which is in correspondence with previous numerous studies (Erman et al., 2011; Zhu et al., 2017; Saadat et al, 2019). AMF symbiosis with plants exerted a variety of positive roles for crop yield in rainfed agricultural system (Al-Karaki \& AlRaddad, 1997; Bryla \& Duniway, 1997; Al-Karaki et al, 2004; Wu \& Xia, 2006). On one hand, AMF inoculation improved plants roots ability to uptake more water from the soil, as well as improved plants root hydraulic properties through higher flexibility of mycorrhizal roots to switch water transport pathways under water stress (Fiorilli et al., 2018; Bernaola \& Stout, 2020). On the other hand, the host plant resistance to drought and plant growth were improvement by AMF symbiosis (Cho et al., 2006; Li et al., 2019). Similarly, Zhang et al. (2019) also concluded that AMF inoculation in field led to $16 \%$ increase on cereal yield, which is the same tendency to our study. Numerous studies have confirmed that the dependency of host plant on AMF was higher in stress environments than in no-stress environments (Latef et al., 2016; Hu et al., 2017; Mohammadzadeh \& Pirzad, 2021). Furthermore, There are differences between grain crops and non-grain crops by AMF, which probably because the positive effect of AMF on yield depends on the plant species (Tarraf et al., 2015). In addition, the effect of AMF inoculation on crop yield was diverse in different functional plant groups. AMF improved more yield of the effect size of $\mathrm{N}$-fixing crops by AMF was higher than non-N-fixing crops (Figure 4). 
369 For N-fixing crops, AMF symbiosis promote rhizobia accumulation in the rhizosphere of host 370 plant and eventually result in increasing yield and biomass (Wang et al., 2021). AMF increase 371 the seed number per plant and pod/fruit number per plant under rainfed condition (Figure 5). The 372 reason may be attributed to the synergistic effect of AMF has increased the number of pods by 373 increasing the absorption of water and nutrients (Rezaie et al., 2020). Although numerous of 374 researches reported that AMF improved crop yield (Espidkar et al., 2017; Zhu et al., 2017;

375 Sharma et al., 2019), some studies involved that the yield benefits of AMF in agroecosystems are 376 often overstated (Duan et al., 2010; Ryan \& Graham, 2018). In conventional agriculture, AMF 377 did not play a vital role due to high fertilizer input and tillage treatments (Ryan et al., 2002). 378 Because the AMF community structure was greatly impacted by the management measures 379 (Jansa et al., 2002, 2003). However, AMF was beneficial to soil and crop in an organic 380 agroecosystem.

381 Numerous studies have testified that AMF increased crop biomass accumulations (Pellegrino 382 et al., 2015; Shao et al., 2018). Our results supported previous finding, which showed that AMF 383 increased 24.2\% shoot biomass and 29.6\% root biomass under rainfed condition (Figure 6). This 384 probably caused by the following reasons. Firstly, AMF promotes plant growth due to improving 385 water status and the availability of soil nutrients by the extension of mycorrhizal hyphae under rainfed condition(Hazzoumi et al., 2015; Püschel et al., 2016). Secondly, AMF mycelium enhanced the uptake scope of roots to nutrients and water (Ruiz-Lozano, 2003; Zhang et al., 388 2019b). In addition, AMF increased host plants biomass (Gosling et al., 2006; Jia-Dong et al., 2019) because the root of host plant absorbed more water that lead to leaves stomata remaining open longer under rainfed condition (Zhu et al., 2012). Further, shoot biomass effect size of Nfixing crops by AMF was higher than non-N-fixing crops (Figure 7), which is possibly lead by stimulating nodulation and nitrogen fixation owing to AMF symbiosis in legume crops (Abbott \& Robson, 1977). Powell (1976) also confirmed that the growth and phosphate uptake of legume 394 plant completely dependent on AMF infection in phosphorus deficient soil. There were differences in root biomass between $\mathrm{N}$-fixing and non-N-fixing crops (Figure 7). AMF increased 396 root biomass of non-N-fixing crops, which also confirmed by Pellegrino \& Bedini (2014). It maybe depends on not only the inactivation of nutrient uptake pathway via root hairs and epidermis but also functional diversity of AMF when non-N-fixing inoculated with AMF 
399 (Klironomos, 2003; Smith ey al., 2004). However, AMF inoculation had no effect on root 400 biomass of N-fixing crops, which may be caused by root nodulation (Suri \& Choudhary, 2013).

401 A decrease in proline and an increase in chlorophyll were observed when inoculated with 402 AMF under rainfed condition (Figure 8). Proline as usual osmoprotectants which stabilize 403 cellular membranes and sustain turgor pressure (Umezawa et al., 2006). The accumulation of 404 proline were increased when plants were under environmental stress (Farhad et al., 2011). The 405 plant inoculated with AMF had lower proline content that presented a negative effect size in 406 Figure 8, compared with non-inoculated plants. It is confirmed that AMF plants have stronger 407 tolerance under rainfed condition. Numerous studies have shown AMF protect their host plant 408 from various environmental stresses such as drought and metal pollution (Kavi Kishor et al., 409 2005; Wu \& Xia, 2006; Shi et al., 2018). The results related to a protection mechanism against 410 abiotic stress by AMF plants. There may be other strategies to deal with environmental stress in 411 AMF plants, such as upregulating the antioxidant defense system and synthesis of osmolytes (Al412 Arjani et al., 2020), which had been also confirmed by numerous previous studies (Porcel \& 413 Ruiz-Lozano, 2004). Rahimzadeh and Pirzad (2017) reported that the chlorophyll content was 414 enhanced in mycorrhizal plants, which is correspondence with our study (Figure 8). The increase 415 of chlorophyll in AMF inoculated plant may be associated with the mobilization of the ions 416 (Amirnia et al., 2019; Ludwig-Müller, 2000).

417 The effects of AMF on plants nutrients content have been widely reported due to its 418 importance in rainfed agriculture. There is a significant increase in $\mathrm{N}$ and $\mathrm{P}$ concentration of 419 shoot in Figure 9. Higher nutrient uptake in mycorrhizal plants might be attributed to the wider 420 absorption surface provided by the hyphae and improvement of soil hydrolytic conductivity, 421 which lead to absorb more nutrients in host plant under stress condition (Smith et al., 2010; 422 Estrada-Campuzano et al, 2012; Rahimzadeh \& Pirzad, 2017). For example, The mycorrhizal 423 plants can use more soluble phosphate than non-inoculated plants by improving nutrient status 424 from rock phosphate (Gyaneshwar et al., 2002). Besides, AMF also can acquire $\mathrm{N}$ and transfer it 425 to host plant by decomposing organic and inorganic material (Govindarajulu et al., 2005; Pérez426 Tienda et al., 2012). AMF inoculation presented no effect on leaf nutrition according to our 427 research (Figure 9). There is also a little study pointed out that AMF infection in the field was 428 apparent ineffectiveness to plant nutrition uptake (McGonigle \& Fitter, 1988). There is evidence 429 that the stimulation of AMF plant growth is suppressed in non-sterile soil by fungivorous 
430 microarthropods grazing the external mycelium (McGonigle \& Fitter, 1988). There were 431 differences in nutrition effect size between seed and shoot. AMF had a positive effect on shoot 432 nutrition (Figure 9) and a neutral effect on seed nutrition (Figure 10), which is similar to Erman 433 et al. (2011). Compared with non-inoculated plant, AMF enhanced nutrition concentration by 434 improving availability of nutrition (Rokhzadi \& Toashih, 2011; Habibzadeh et al., 2013).

435 Structural equation model analysis showed that the relationship between AMF, biomass and 436 yield, which indicated that AMF increased yield by increasing biomass under rainfed condition 437 (Figure 11). AMF synergistic interaction increased plant growth by providing the essential 438 nutrients for host plant (Lingua et al., 2013). For example, AMF inoculation increased N, P and 439 K uptake by plants under water deficit conditions (Malfanova et al., 2011). Especially under 440 drought conditions, AMF inoculated improved plant growth and water status due to the higher 441 stomatal conductance in host plants than the control plants (Naseri et al., 2013). This possibly 442 related to the hyphal extensions of AMF that allow higher hydraulic conductivity than non-AMF 443 (Askari et al., 2019). Therefore, symbiotic relationship between AMF and host plants played a 444 beneficial role in improving yield of the host plant under rainfed condition.

445

\section{Conclusions}

447 AMF obviously increased crop yields under rainfed condition. The effect of AMF on crop yields 448 depended on crop functional groups in rainfed agroecosystem. Our study highlighted that AMF 449 increase crop yield by improving shoot biomass in rainfed agriculture. The shoot biomass of 450 inoculated plant enhanced by improving plant nutrients, photosynthesis and stress resistance. Our 451 findings provided a new view for understanding the sustainable productivity in rainfed 452 agroecosystem, which enriched the theory of AMF functional diversity.

\section{Acknowledgements}

455 This research was funded by National Natural Science Foundation of China (32171620, 456 31670499), Henan Provincial Science and Technology Research Project (192102110128), Henan 457 Province University Innovation Talents Support Program (18HASTIT013), Key Laboratory of 458 Mountain Surface Processes and Ecological Regulation, CAS (20160618).

459 ADDITIONAL INFORMATION AND DECLARATIONS 


\section{Competing Interests}

461 The authors declare that they have no competing interests.

\section{Author Contribution}

463 - Shanwei Wu performed the search strategy, conceived and designed the experiments,

464 performed the experiments, analyzed the data, prepared the figures, authored or reviewed drafts 465 of the paper, and approved the final draft.

466 - Zhaoyong Shi conceived and designed the experiments, performed the experiments, analyzed 467 the data, prepared the figures, authored or reviewed drafts of the paper, and approved the final 468 draft.

469 - Xianni Chen performed the search strategy, performed the experiments, analyzed the data, 470 authored or reviewed drafts of the paper, and approved the final draft.

471 - Jiakai Gao analyzed the data, prepared the figures, authored or reviewed drafts of the paper, 472 and approved the final draft.

473 - Xugang Wang performed the experiments, analyzed the data, prepared the figures, authored or 474 reviewed drafts of the paper, and approved the final draft.

\section{Data Availability}

476 The following information was supplied regarding data availability:

477 The Global Dataset of Arbuscular Mycorrhizal Fungi and Crop Yields under Rainfed 478 Agroecosystem is available in the Supplemental Files.

479 Additional Supporting Information (Note S and Figure S) is available in the Supplemental Files. 480

\section{References}

Abbott LK, Robson AD. 1977. Growth stimulation of subterranean clover with vesicular arbuscular mycorrhizas. Australian Journal of Agricultural Research 28:639-649. DOI: 10.1071/AR9770639.

Abera K, Crespo O, Seid J, Mequanent F. 2018. Simulating the impact of climate change on maize production in Ethiopia, East Africa. Environmental Systems Research 7. DOI: 10.1186/S40068-018-0107-Z. 
489

490

491

492

493

494

495

496

497

498

499

500

501

502

503

504

505

506

507

508

509

510

511

512

513

514

515

516

517

518

519

Ahmed M, Fayyaz-Ul-Hassan. 2015. Response of spring wheat (Triticum aestivum L.) quality traits and yield to sowing date. PLoS ONE 10. DOI: 10.1371/JOURNAL.PONE.0126097.

Al-Arjani ABF, Hashem A, Abd_Allah EF. 2020. Arbuscular mycorrhizal fungi modulates dynamics tolerance expression to mitigate drought stress in Ephedra foliata Boiss. Saudi Journal of Biological Sciences 27:380-394. DOI: 10.1016/j.sjbs.2019.10.008.

Al-Karaki GN, Al-Raddad A. 1997. Effects of arbuscular mycorrhizal fungi and drought stress on growth and nutrient uptake of two wheat genotypes differing in drought resistance. Mycorrhiza 7:83-88. DOI: 10.1007/s005720050166.

Al-Karaki G, McMichael B, Zak J. 2004. Field response of wheat to arbuscular mycorrhizal fungi and drought stress. Mycorrhiza 14:263-269. DOI: 10.1007/s00572-003-0265-2.

Amirnia R, Ghiyasi M, Siavash Moghaddam S, Rahimi A, Damalas CA, Heydarzadeh S. 2019. Nitrogen-Fixing Soil Bacteria Plus Mycorrhizal Fungi Improve Seed Yield and Quality Traits of Lentil (Lens culinaris Medik). Journal of Soil Science and Plant Nutrition 19:592-602. DOI: 10.1007/s42729-019-00058-3.

Ardakani MR, Pietsch G, Moghaddam A, Raza A, Friedel JK. 2009. Response of root properties to tripartite symbiosis between lucerne (Medicago sativa L.), rhizobia and mycorrhiza under dry organic farming conditions. American Journal of Agricultural and Biological Science 4:266-277. DOI: 10.3844/ajabssp.2009.266.277.

Askari A, Ardakani MR, Paknejad F, Hosseini Y. 2019. Effects of mycorrhizal symbiosis and seed priming on yield and water use efficiency of sesame under drought stress condition. Scientia Horticulturae 257. DOI: 10.1016/j.scienta.2019.108749.

Augé RM, Toler HD, Saxton AM. 2015. Arbuscular mycorrhizal symbiosis alters stomatal conductance of host plants more under drought than under amply watered conditions: a meta-analysis. Mycorrhiza 25:13-24. DOI: 10.1007/s00572-014-0585-4.

Bakhshandeh S, Corneo PE, Mariotte P, Kertesz MA, Dijkstra FA. 2017. Effect of crop rotation on mycorrhizal colonization and wheat yield under different fertilizer treatments. Agriculture, Ecosystems and Environment 247:130-136. DOI: 10.1016/j.agee.2017.06.027.

Bárzana G, Aroca R, Bienert GP, Chaumont F, Ruiz-Lozano JM. 2014. New insights into the regulation of aquaporins by the arbuscular mycorrhizal symbiosis in maize plants under drought stress and possible implications for plant performance. Molecular Plant-Microbe Interactions 27:349-363. DOI: 10.1094/MPMI-09-13-0268-R. 
520 Bernaola L, Stout MJ. 2020. The effect of mycorrhizal seed treatments on rice growth, yield,

521

522

523

524

525

526

527

528

529

530

531

532

533

534

535

536

537

538

539

540

541

542

543

544

545

546

547

548

549

550 and tolerance to insect herbivores. Journal of Pest Science 94:375-392. DOI: 10.1007/S10340-020-01279-7.

Birara H, Pandey RP, Mishra SK. 2018. Trend and variability analysis of rainfall and temperature in the tana basin region, Ethiopia. Journal of Water and Climate Change 9:555-569. DOI: 10.2166/WCC.2018.080.

Bryla DR, Duniway JM. 1997. Growth, phosphorus uptake, and water relations of safflower and wheat infected with an arbuscular mycorrhizal fungus. New Phytologist 136:581-590. DOI: 10.1046/j.1469-8137.1997.00780.x.

Cavagnaro TR, Bender SF, Asghari HR, van der Heijden MGA. 2015. The role of arbuscular mycorrhizas in reducing soil nutrient loss. Trends in Plant Science 20:283-290. DOI: 10.1016/j.tplants.2015.03.004.

Celebi SZ, Demir S, Celebi R, Durak ED, Yilmaz IH. 2010. The effect of Arbuscular Mycorrhizal Fungi (AMF) applications on the silage maize (Zea mays L.) yield in different irrigation regimes. European Journal of Soil Biology 46:302-305. DOI: 10.1016/j.ejsobi.2010.06.002.

Chitarra W, Pagliarani C, Maserti B, Lumini E, Siciliano I, Cascone P, Schubert A, Gambino G, Balestrini R, Guerrieri E. 2016. Insights on the impact of arbuscular mycorrhizal symbiosis on tomato tolerance to water stress. Plant Physiology 171:10091023. DOI: $10.1104 /$ pp.16.00307.

Cho K, Toler H, Lee J, Ownley B, Stutz JC, Moore JL, Augé RM. 2006. Mycorrhizal symbiosis and response of sorghum plants to combined drought and salinity stresses. Journal of Plant Physiology 163:517-528. DOI: 10.1016/j.jplph.2005.05.003.

Dowarah B, Gill SS, Agarwala N. 2021. Arbuscular Mycorrhizal Fungi in Conferring Tolerance to Biotic Stresses in Plants. Journal of Plant Growth Regulation. DOI: 10.1007/s00344-021-10392-5.

DOWNTON WJS, LOVEYS BR, GRANT WJR. 1988. Non-uniform stomatal closure induced by water stress causes putative non-stomatal inhibition of photosynthesis. New Phytologist 110:503-509. DOI: 10.1111/j.1469-8137.1988.tb00289.x.

Duan T, Shen Y, Facelli E, Smith SE, Nan Z. 2010. New agricultural practices in the Loess Plateau of China do not reduce colonisation by arbuscular mycorrhizal or root invading 
551

552

553

554

555

556

557

558

559

560

561

562

563

564

565

566

567

568

569

570

571

572

573

574

575

576

577

578

579

580

581

fungi and do not carry a yield penalty. Plant and Soil 331:265-275. DOI: 10.1007/S11104009-0251-3.

Erman M, Demir S, Ocak E, Tüfenkçi Ş, Oĝuz F, Akköprü A. 2011. Effects of Rhizobium, arbuscular mycorrhiza and whey applications on some properties in chickpea (Cicer arietinum L.) under irrigated and rainfed conditions 1-Yield, yield components, nodulation and AMF colonization. Field Crops Research 122:14-24. DOI: 10.1016/j.fcr.2011.02.002.

Espidkar Z, Yarnia M, Ansari MH, Mirshekari B, Asadi Rahmani H. 2017. Differences in nitrogen and phosphorus uptake and yield components between barley cultivars grown under arbuscular mycorrhizal fungus and pseudomonas strains Co-Inoculation in rainfed condition. Applied Ecology and Environmental Research 15:195-216. DOI: 10.15666/aeer/1504_195216.

Estrada-Campuzano G, Slafer GA, Miralles DJ. 2012. Differences in yield, biomass and their components between triticale and wheat grown under contrasting water and nitrogen environments. Field Crops Research 128:167-179. DOI: 10.1016/j.fcr.2012.01.003.

Farhad MS, Babak AM, Reza ZM, Hassan RSM, Afshin T. 2011. Response of proline, soluble sugars, photosynthetic pigments and antioxidant enzymes in potato (Solanum tuberosum L.) to different irrigation regimes in greenhouse condition. Australian Journal of Crop Science 5:55-60.

Fiorilli V, Vannini C, Ortolani F, Garcia-Seco D, Chiapello M, Novero M, Domingo G, Terzi V, Morcia C, Bagnaresi P, Moulin L, Bracale M, Bonfante P. 2018. Omics approaches revealed how arbuscular mycorrhizal symbiosis enhances yield and resistance to leaf pathogen in wheat. Scientific Reports 8:1-18. DOI: 10.1038/s41598-018-27622-8.

Foo YZ, Koricheva J, Nakagawa S, Lagisz M. 2021. Methods in Ecology and Evolution. DOI: 10.1111/2041-210X.13654.

Gan YT, Siddique KHM, Turner NC, Li XG, Niu JY, Yang C, Liu LP, Chai Q. 2013. Ridge-furrow mulching systems - an innovative technique for boosting crop productivity in semiarid rain-fed environments. Advance in agronomy 118:429-476. DOI: 10.1016/B978-012-405942-9.00007-4.

Gebrechorkos SH, Hülsmann S, Bernhofer C. 2019. Long-term trends in rainfall and temperature using high-resolution climate datasets in East Africa. Scientific Reports 9. DOI: 10.1038/S41598-019-47933-8. 
582 Giordano M, Fraiture C De, Weight E, Bliek J Van Der. 2012. Water for wealth and food

583

584

585

586

587

588

589

590

591

592

593

594

595

596

597

598

599

600

601

602

603

604

605

606

607

608

609

610

611 security Water for wealth and food security: Supporting farmer-driven investmenst in agricultural water management.

Giroux AJOJМММJ. 2019. Yield increases resulting from AGPase overexpression in rice are reliant on plant nutritional status. Plant Growth Regulation 89:179-190. DOI: 10.1007/s10725-019-00525-y.

Gosling P, Hodge A, Goodlass G, Bending GD. 2006. Arbuscular mycorrhizal fungi and organic farming. Agriculture, Ecosystems and Environment 113:17-35. DOI: 10.1016/j.agee.2005.09.009.

Govindarajulu M, Pfeffer PE, Jin H, Abubaker J, Douds DD, Allen JW, Bücking H, Lammers PJ, Shachar-Hill Y. 2005. Nitrogen transfer in the arbuscular mycorrhizal symbiosis. Nature 435:819-823. DOI: 10.1038/nature03610.

Gyaneshwar P, Naresh Kumar G, Parekh LJ, Poole PS. 2002. Role of soil microorganisms in improving P nutrition of plants. Plant and Soil 245:83-93. DOI: 10.1023/A:1020663916259.

Habibzadeh Y, Pirzad A, Reza Zardashti M, Jalilian J, Eini O. 2013. Effects of arbuscular mycorrhizal fungi on seed and protein yield under water-deficit stress in mung bean. Agronomy Journal 105:79-84. DOI: 10.2134/agronj2012.0069.

Hazzoumi Z, Moustakime Y, hassan Elharchli E, Joutei KA. 2015. Effect of arbuscular mycorrhizal fungi (AMF) and water stress on growth, phenolic compounds, glandular hairs, and yield of essential oil in basil (Ocimum gratissimum L). Chemical and Biological Technologies in Agriculture 2. DOI: 10.1186/s40538-015-0035-3.

Heidari M, Karami V. 2014. Effects of different mycorrhiza species on grain yield, nutrient uptake and oil content of sunflower under water stress. Journal of the Saudi Society of Agricultural Sciences 13:9-13. DOI: 10.1016/j.jssas.2012.12.002.

Hijri M. 2016. Analysis of a large dataset of mycorrhiza inoculation field trials on potato shows highly significant increases in yield. Mycorrhiza 26:209-214. DOI: 10.1007/S00572-0150661-4.

Hoeksema JD, Chaudhary VB, Gehring CA, Johnson NC, Karst J, Koide RT, Pringle A, Zabinski C, Bever JD, Moore JC, Wilson GWT, Klironomos JN, Umbanhowar J. 
612

613

614

615

616

617

618

619

620

621

622

623

624

625

626

627

628

629

630

631

632

633

634

635

636

637

638

639

640

641

2010. A meta-analysis of context-dependency in plant response to inoculation with mycorrhizal fungi. Ecology Letters 13:394-407. DOI: 10.1111/j.1461-0248.2009.01430.x.

Hu W, Zhang H, Chen H, Tang M. 2017. Arbuscular mycorrhizas influence Lycium barbarum tolerance of water stress in a hot environment. Mycorrhiza 27:451-463. DOI: 10.1007/s00572-017-0765-0.

Jansa J, Mozafar A, Anken T, Ruh R, Sanders IR, Frossard E. 2002. Diversity and structure of AMF communities as affected by tillage in a temperate soil. Mycorrhiza 12: 225-234. DOI: $10.1007 / \mathrm{s} 00572-002-0163-z$

Jansa J, Mozafar A, Kuhn G, Anken T, Ruh R, Sanders IR, Frossard E. 2003. Soil tillage affects the community structure of mycorrhizal fungi in maize roots. Ecological Applications 13: 1164-1176. DOI: 10.1890/1051-0761(2003)13[1164:STATCS]2.0.CO;2.

Jia-Dong H, Tao D, Hui-Hui W, Zou YN, Wu QS, Kamil K. 2019. Mycorrhizas induce diverse responses of root TIP aquaporin gene expression to drought stress in trifoliate orange. Scientia Horticulturae 243:64-69. DOI: 10.1016/j.scienta.2018.08.010.

Jiang J, Wang YP, Yang Y, Yu M, Wang C, Yan J. 2019. Interactive effects of nitrogen and phosphorus additions on plant growth vary with ecosystem type. Plant and Soil 440:523537. DOI: 10.1007/s11104-019-04119-5.

Jin N, Tao B, Ren W, Feng M, Sun R, He L, Zhuang W, Yu Q. 2016. Mapping irrigated and rainfed wheat areas using multi-temporal satellite data. Remote Sensing 8. DOI: $10.3390 /$ rs 8030207 .

Johnson D, Martin F, Cairney JWG, Anderson IC. 2012. The importance of individuals: Intraspecific diversity of mycorrhizal plants and fungi in ecosystems. New Phytologist 194:614-628. DOI: 10.1111/j.1469-8137.2012.04087.x.

Karaca H, Uygur V, Özkan A, Kaya Z. 2013. Effects of Mycorrhizae and Fertilization on Soybean Yield and Nutrient Uptake. Communications in Soil Science and Plant Analysis 44:2459-2471. DOI: 10.1080/00103624.2013.809730.

Kavi Kishor PB, Sangam S, Amrutha RN, Sri Laxmi P, Naidu KR, Rao KRSS, Rao S, Reddy KJ, Theriappan P, Sreenivasulu N. 2005. Regulation of proline biosynthesis, degradation, uptake and transport in higher plants: Its implications in plant growth and abiotic stress tolerance. Current Science 88:424-438.

Peer] reviewing PDF | (2021:07:63448:2:0:NEW 16 Dec 2021) 
642 Klironomos JN. 2003. Variation in plant response to native and exotic arbuscular mycorrhizal 643 fungi. Ecology 84:2292-2301. DOI: 10.1890/02-0413.

644 Koide RT. 2003. Is plant performance limited by abundance of arbuscular mycorrhizal fungi ? A 645 meta-analysis of studies published between 1988 and 2003. New Phytologist, 168(1), 189646 204. doi:10.1111/j.1469-8137.2005.01490.x

647 Kumar A, Meena RS, Nirmal DE, Gurjar DS, Singh A, Yadav GS, Pradhan G. 2020.

648 Response of polymers and biofertilizers on soybean (Glycine max) yield under rainfed 649 condition. Indian Journal of Agricultural Sciences 90:767-770.

650

651

652

Latef AAHA, Hashem A, Rasool S, Abd-Allah EF, Alqarawi AA, Egamberdieva D, Jan S, Anjum NA, Ahmad P. 2016. Arbuscular mycorrhizal symbiosis and abiotic stress in 653 plants: A review. Journal of Plant Biology 59:407-426. DOI: 10.1007/s12374-016-0237-7.

Li J, Meng B, Chai H, Yang X, Song W, Li S, Lu A, Zhang T, Sun W. 2019. Arbuscular 654 mycorrhizal fungi alleviate drought stress in C3 (Leymus chinensis) and C4 (hemarthria

655

656 altissima) grasses via altering antioxidant enzyme activities and photosynthesis. Frontiers in Plant Science 10:1-12. DOI: 10.3389/fpls.2019.00499.

657

Li T, Sun Y, Ruan Y, Xu L, Hu Y, Hao Z, Zhang X, Li H, Wang Y, Yang L, Chen B. 2016.

658

659 Potential role of D-myo-inositol-3-phosphate synthase and 14-3-3 genes in the crosstalk

660 between Zea mays and Rhizophagus intraradices under drought stress. Mycorrhiza 26:879_-

661 893. DOI: $10.1007 / \mathrm{s} 00572-016-0723-2$.

662

Licker R, Johnston M, Foley JA, Barford C, Kucharik CJ, Monfreda C, Ramankutty N, Sage E, Nelson G. 2010. Mind the gap : how do climate and agricultural management

663 explain the 'yield gap' of croplands around the world ? Global Ecology and Biogeogr. 19:

664 769-782. DOI: 10.1111/j.1466-8238.2010.00563.x.

665

van der Linden S, Goldberg MH. 2020. Alternative meta-analysis of behavioral interventions 666 to promote action on climate change yields different conclusions. Nature Communications

667 11. DOI: $10.1038 / \mathrm{S} 41467-020-17613-7$.

Lingua G, Bona E, Manassero P, Marsano F, Todeschini V, Cantamessa S, Copetta A, 669 D’Agostino G, Gamalero E, Berta G. 2013. Arbuscular mycorrhizal fungi and plant 670 671 672 growth-promoting pseudomonads increases anthocyanin concentration in strawberry fruits (Fragaria x ananassa var. Selva) in conditions of reduced fertilization. International Journal of Molecular Sciences 14:16207-16225. DOI: 10.3390/ijms140816207. 
673 Ludwig-Müller J. 2000. Hormonal Balance in Plants During Colonization by Mycorrhizal 674 Fungi. In: Arbuscular Mycorrhizas: Physiology and Function. Springer Netherlands, 263675 285. DOI: $10.1007 / 978-94-017-0776-3 \_12$.

676 Malfanova N, Kamilova F, Validov S, Shcherbakov A, Chebotar V, Tikhonovich I, 677 Lugtenberg B. 2011. Characterization of Bacillus subtilis HC8, a novel plant-beneficial 678 endophytic strain from giant hogweed. Microbial Biotechnology 4:523-532. DOI:

679 10.1111/j.1751-7915.2011.00253.x.

McGonigle TP, Fitter AH. 1988. Growth and phosphorus inflows of Trifolium repens L. with a range of indigenous vesicular-arbuscular mycorrhizal infection levels under field conditions. New Phytologist 108:59-65. DOI: 10.1111/j.1469-8137.1988.tb00204.x.

Mirshad PP, Puthur JT. 2016. Arbuscular mycorrhizal association enhances drought tolerance potential of promising bioenergy grass (Saccharum arundinaceum retz.). Environmental Monitoring and Assessment 188. DOI: 10.1007/s10661-016-5428-7.

Mohammadzadeh S, Pirzad A. 2021. Biochemical responses of mycorrhizal-inoculated Lamiaceae (Lavender, Rosemary and Thyme) plants to drought: a field study. Soil Science and Plant Nutrition 67:41-49. DOI: 10.1080/00380768.2020.1851144.

Moher D, Shamseer L, Clarke M, Ghersi D, Liberati A, Petticrew M, Shekelle P, Stewart LA, Estarli M, Barrera ESA, Martínez-Rodríguez R, Baladia E, Agüero SD, Camacho S, Buhring K, Herrero-López A, Gil-González DM, Altman DG, Booth A, Chan AW, Chang S, Clifford T, Dickersin K, Egger M, Gøtzsche PC, Grimshaw JM, Groves T, Helfand M, Higgins J, Lasserson T, Lau J, Lohr K, McGowan J, Mulrow C, Norton M, Page M, Sampson M, Schünemann H, Simera I, Summerskill W, Tetzlaff J, Trikalinos TA, Tovey D, Turner L, Whitlock E. 2016. Preferred reporting items for systematic review and meta-analysis protocols (PRISMA-P) 2015 statement. Revista Espanola de Nutricion Humana y Dietetica 20:148-160. DOI: 10.1186/2046-4053-4-1.

Molden D, Vithanage M, de Fraiture C, Faures JM, Gordon L, Molle F, Peden D. 2011. Water Availability and Its Use in Agriculture. In: Treatise on Water Science. Elsevier, 707732. DOI: 10.1016/B978-0-444-53199-5.00108-1.

Molle F. 2008. "Water for food, water for life: A comprehensive assessment of water management in agriculture" david molden (Ed.): Compte rendu de document 
703

704

705

706

707

708

709

710

711

712

713

714

715

716

717

718

719

720

721

722

723

724

725

726

727

728

729

730

731

732

(IWMI/Earthscan, 2007). Natures Sciences Societes 16:274-275. DOI:

10.1051/nss:2008056.

Naseri R, Azadi S, Rahimi MJ, Maleki A, Mirzaei A. 2013. Effects of inoculation with Azotobacter Chroococcum and Pseudomonas putida on yield and some of the important agronomic traits in barley ( Hordeum vulgar L .). 4:1602-1610.

Pellegrino E, Bedini S. 2014. Enhancing ecosystem services in sustainable agriculture: Biofertilization and biofortification of chickpea (Cicer arietinum L.) by arbuscular mycorrhizal fungi. Soil Biology and Biochemistry 68:429-439. DOI:

10.1016/j.soilbio.2013.09.030.

Pellegrino E, Öpik M, Bonari E, Ercoli L. 2015. Responses of wheat to arbuscular mycorrhizal fungi: A meta-analysis of field studies from 1975 to 2013. Soil Biology and Biochemistry 84:210-217. DOI: 10.1016/j.soilbio.2015.02.020.

Pérez-Tienda J, Valderas A, Camañes G, García-Agustín P, Ferrol N. 2012. Kinetics of NH4+uptake by the arbuscular mycorrhizal fungus Rhizophagus irregularis. Mycorrhiza 22:485-491. DOI: 10.1007/s00572-012-0452-0.

Porcel R, Aroca R, Azcón R, Ruiz-Lozano JM. 2006. PIP aquaporin gene expression in arbuscular mycorrhizal Glycine max and Lactuca sativa plants in relation to drought stress tolerance. Plant Molecular Biology 60:389-404. DOI: 10.1007/s11103-005-4210-y.

Porcel R, Ruiz-Lozano JM. 2004. Arbuscular mycorrhizal influence on leaf water potential, solute accumulation, and oxidative stress in soybean plants subjected to drought stress. Journal of Experimental Botany 55:1743-1750. DOI: 10.1093/jxb/erh188.

Powell C. 1976. Mycorrhizal fungi stimulate clover growth in New Zealand hill country soils. Nature 264:436-438. DOI: 10.1038/264436a0.

Püschel D, Janoušková M, Hujslová M, Slavíková R, Gryndlerová H, Jansa J. 2016. Plantfungus competition for nitrogen erases mycorrhizal growth benefits of Andropogon gerardii under limited nitrogen supply. Ecology and Evolution 6:4332-4346. DOI: 10.1002/ece3.2207.

Qin W, Wang D, Guo X, Yang T, Oenema O. 2015. Productivity and sustainability of rainfed wheat-soybean system in the North China Plain: results from a long-term experiment and crop modelling OPEN. Nature Publishing Group 5:17514. DOI: 10.1038/srep17514. 
733 Quiroga G, Erice G, Aroca R, Chaumont F, Ruiz-Lozano JM. 2017. Enhanced drought stress

734

735

736

737

738

739

740

741

742

743

744

745

746

747

748

749

750

751

752

753

754

755

756

757

758

759

760

761

762

763

tolerance by the arbuscular mycorrhizal symbiosis in a drought-sensitive maize cultivar is related to a broader and differential regulation of host plant aquaporins than in a droughttolerant cultivar. Frontiers in Plant Science 8. DOI: 10.3389/fpls.2017.01056.

Rahimzadeh S, Pirzad A. 2017. Arbuscular mycorrhizal fungi and Pseudomonas in reduce drought stress damage in flax (Linum usitatissimum L.): a field study. Mycorrhiza 27:537552. DOI: 10.1007/s00572-017-0775-y.

Rezaie MA, Pasari B, Mohammadi K, Rokhzadi A, Karami E. 2020. Study the effect of mycorrizal fungi, chitosan and cycocel on agronomic characteristics of rainfed chickpea. Legume Research 43:546-551. DOI: 10.18805/LR-509.

Rillig MC, Sosa-Hernández MA, Roy J, Aguilar-Trigueros CA, Vályi K, Lehmann A. 2016. Towards an integrated mycorrhizal technology: Harnessing mycorrhiza for sustainable intensification in agriculture. Frontiers in Plant Science 7. DOI: 10.3389/fpls.2016.01625.

Rokhzadi A, Toashih V. 2011. Nutrient uptake and yield of chickpea (Cicer arietinum L.) inoculated with plant growth-promoting rhizobacteria. Australian Journal of Crop Science 5:44-48.

Rosegrant M, Cai X, Cline S, Nakagawa N. 2002. The Role of Rainfed Agriculture in the Future of Global Food Production. Environment and Production Technology Division: Washington, DC, USA.

Rosseel Y. 2012. Lavaan: An R package for structural equation modeling. Journal of Statistical Software 48. DOI: 10.18637/jss.v048.i02.

Ruiz-Lozano JM. 2003. Arbuscular mycorrhizal symbiosis and alleviation of osmotic stress. New perspectives for molecular studies. Mycorrhiza 13:309-317. DOI: 10.1007/s00572003-0237-6.

Ruiz-Sánchez M, Aroca R, Muñoz Y, Polón R, Ruiz-Lozano JM. 2010. The arbuscular mycorrhizal symbiosis enhances the photosynthetic efficiency and the antioxidative response of rice plants subjected to drought stress. Journal of Plant Physiology 167:862869. DOI: 10.1016/j.jplph.2010.01.018.

Ryan MH, Graham JH. 2018. Little evidence that farmers should consider abundance or diversity of arbuscular mycorrhizal fungi when managing crops. New Phytologist 220:1092-1107. DOI: 10.1111/NPH.15308.

Peer] reviewing PDF | (2021:07:63448:2:0:NEW 16 Dec 2021) 
764 Ryan MH, Graham JH. 2002. Is there a role for arbuscular mycorrhizal fungi in production

765

766

767

768

769

770

771

772

773

774

775

776

777

778

779

780

781

782

783

784

785

786

787

788

789

790

791

792

793 agriculture? Plant and Soil 244: 263-271. DOI: 10.1023/a:1020207631893

Saadat B, Pirzad A, Jalilian J. 2019. How do AMF-inoculation and supplemental irrigation affect the productivity of rainfed yellow sweet clover in agrisilviculture systems? Archives of Agronomy and Soil Science 65:2043-2058. DOI: 10.1080/03650340.2019.1600674.

Salvagiotti F, Cassman KG, Specht JE, Walters DT, Weiss A, Dobermann A. 2008. Nitrogen uptake, fixation and response to fertilizer $\mathrm{N}$ in soybeans: A review. Field Crops Research 108:1-13. DOI: 10.1016/j.fcr.2008.03.001.

Saxena SC, Salvi P, Kaur H, Verma P, Petla BP, Rao V, Kamble N, Majee M. 2013. Differentially expressed myo-inositol monophosphatase gene (CaIMP) in chickpea (Cicer arietinum L.) encodes a lithium-sensitive phosphatase enzyme with broad substrate specificity and improves seed germination and seedling growth under abiotic stresses. Journal of Experimental Botany 64:5623-5639. DOI: 10.1093/JXB/ERT336.

Schütz L, Gattinger A, Meier M, Müller A, Boller T, Mäder P and Mathimaran N. 2018. Improving Crop Yield and Nutrient Use Efficiency via Biofertilization-A Global Metaanalysis. Frontiers in Plant Science. 8:2204. DOI: 10.3389/fpls.2017.02204

Setiyono TD, Walters DT, Cassman KG, Witt C, Dobermann A. 2010. Estimating maize nutrient uptake requirements. Field Crops Research 118:158-168. DOI: 10.1016/j.fcr.2010.05.006.

Shao YD, Zhang DJ, Hu XC, Wu QS, Jiang CJ, Xia TJ, Gao XB, Kuča K. 2018. Mycorrhiza-induced changes in root growth and nutrient absorption of tea plants. Plant, Soil and Environment 64:283-289. DOI: 10.17221/126/2018-PSE.

Sharma V, Sharma S, Sharma S, Kumar V. 2019. Synergistic effect of bio-inoculants on yield, nodulation and nutrient uptake of chickpea (Cicer arietinum L) under rainfed conditions. Journal of Plant Nutrition 42:374-383. DOI: 10.1080/01904167.2018.1555850.

Sharma AK, Singh SP. 2016. Effect of amino acids on the repression of alkaline protease synthesis in haloalkaliphilic Nocardiopsis dassonvillei. Biotechnology Reports 12:40-51. DOI: $10.1016 /$ j.btre.2016.10.004.

Shi Z Y, Zhang J C, Wang F Y, Li K, Yuan W K and Liu J B. 2018. Arbuscula mycorrhizal inoculation increases molybdenum accumulation but decreases molybdenum toxicity in 
794

795

796

797

798

799

800

801

802

803

804

805

806

807

808

809

810

811

812

813

814

815

816

817

818

819

820

821

822

823

824

maize plants grown in polluted soil. Royal Society of Chemistry 8: 37069-37076. DOI: $10.1039 / \mathrm{c} 8 \mathrm{ra0} 07725 \mathrm{~h}$

Smith SE, Facelli E, Pope S, Smith FA. 2010. Plant performance in stressful environments: Interpreting new and established knowledge of the roles of arbuscular mycorrhizas. Plant and Soil 326:3-20. DOI: 10.1007/s11104-009-9981-5.

Smith S, Read D. 2008. Mycorrhizal Symbiosis. Academic Press. San Diego, USA. DOI: 10.1016/B978-0-12-370526-6.X5001-6.

Smith SE, Smith FA, Jakobsen I. 2004. Functional diversity in arbuscular mycorrhizal (AM) symbioses: The contribution of the mycorrhizal P uptake pathway is not correlated with mycorrhizal responses in growth or total P uptake. New Phytologist 162:511-524. DOI: 10.1111/J.1469-8137.2004.01039.X.

Song C, Peacor SD, Osenberg CW, Bence JR, Lansing E. 2020. An assessment of statistical methods for non-independent data in ecological meta-analyses. Ecology, 101(12). doi:10.1002/ecy.3184.

Sterne JAC, Egger M. 2001. Funnel plots for detecting bias in meta-analysis: Guidelines on choice of axis. Journal of Clinical Epidemiology 54:1046-1055. DOI: 10.1016/S08954356(01)00377-8.

Sun J, Yang L, Yang X, Wei J, Li L, Guo E, Kong Y. 2021. Using Spectral Reflectance to Estimate the Leaf Chlorophyll Content of Maize Inoculated With Arbuscular Mycorrhizal Fungi Under Water Stress. Frontiers in Plant Science 12:1-12. DOI: 10.3389/fpls.2021.646173.

Suri VK, Choudhary AK. 2013. Effects of Vesicular Arbuscular Mycorrhizae and Applied Phosphorus through Targeted Yield Precision Model on Root Morphology, Productivity, and Nutrient Dynamics in Soybean in an Acid Alfisol. Communications in Soil Science and Plant Analysis 44:2587-2604. DOI: 10.1080/00103624.2013.803569.

Tarraf W, Ruta C, De Cillis F, Tagarelli A, Tedone L, De Mastro G. 2015. Effects of mycorrhiza on growth and essential oil production in selected aromatic plants. Italian Journal of Agronomy 10:160-162. DOI: 10.4081/ija.2015.633.

Thirkell TJ, Charters MD, Elliott AJ, Sait SM, Field KJ. 2017. Are mycorrhizal fungi our sustainable saviours? Considerations for achieving food security. Journal of Ecology 105:921-929. DOI: 10.1111/1365-2745.12788. 
825 UNESCO. 2009. The United Nations World Water Development Reported 3: Water in a

826 Changing World. UNESCO. Earthscan: Paris, France; London, UK.

827 Umezawa T, Okamoto M, Kushiro T, Nambara E, Oono Y, Seki M, Kobayashi M, Koshiba

828 T, Kamiya Y, Shinozaki K. 2006. CYP707A3, a major ABA 8'-hydroxylase involved in

829 dehydration and rehydration response in Arabidopsis thaliana. The Plant Journal 46:171-

830 182. DOI: 10.1111/J.1365-313X.2006.02683.X.

831 Viechtbauer W. 2010. Conducting meta-analyses in R with the metafor. Journal of Statistical 832 Software 36:1-48. DOI: 10.18637/jss.v036.i03.

833 Wang X, Feng H, Wang Y, Wang M, Xie X, Chang H, Wang L, Qu J, Sun K, He W, Wang 834 C, Dai C, Chu Z, Tian C, Yu N, Zhang X, Liu H, Wang E. 2021. Mycorrhizal symbiosis 835 modulates the rhizosphere microbiota to promote rhizobia-legume symbiosis. Molecular 836 Plant 14:503-516. DOI: 10.1016/j.molp.2020.12.002.

837 Wang J, Wang Y, Song X, Wang Y, Lei X. 2017. Elevated Atmospheric $\mathrm{CO}_{2}$ and Drought 838 Affect Soil Microbial Community and Functional Diversity Associated with Glycine max. Revista Brasileira de Ciência do Solo 41:160460. DOI: 10.1590/18069657RBCS20160460.

Wu QS, Xia RX. 2006. Arbuscular mycorrhizal fungi influence growth, osmotic adjustment and photosynthesis of citrus under well-watered and water stress conditions. Journal of Plant Physiology 163:417-425. DOI: 10.1016/j.jplph.2005.04.024.

844

845

Xu A, Li L, Coulter JA, Xie J, Zhang R, Luo Z, Cai L, Liu C, Wang L. 2021. Long-term nitrogen addition impact on agronomic traits, nitrogen uptake and nitrogen resorption efficiency of wheat in a rainfed region. Soil Science Society of America Journal 85:452467. DOI: $10.1002 /$ saj2.20172.

Yadav SS, Redden RJ, Hatfield JL, Ebert AW, Hunter D. 2018. Food Security and Climate Change. Food Security and Climate Change. DOI: 10.1002/9781119180661. respiration of subtropical forests with different successional stages in south China. Forest Ecology and Management 243:178-186. DOI: 10.1016/J.FORECO.2007.02.022. 10.1111/nph.15570. 
855 Zhang F, Wang P, Zou YN, Wu QS, Kuča K. 2019b. Effects of mycorrhizal fungi on root-hair 856 growth and hormone levels of taproot and lateral roots in trifoliate orange under drought 857 stress. Archives of Agronomy and Soil Science 65:1316-1330. DOI:

$858 \quad 10.1080 / 03650340.2018 .1563780$.

859 Zhu Y, Lv GC, Chen YL, Gong XF, Peng YN, Wang ZY, Ren AT, Xiong YC. 2017.

860 Inoculation of arbuscular mycorrhizal fungi with plastic mulching in rainfed wheat: A

861 promising farming strategy. Field Crops Research 204:229-241. DOI:

$862 \quad$ 10.1016/j.fcr.2016.11.005.

863 Zhu XC, Song FB, Liu SQ, Liu TD, Zhou X. 2012. Arbuscular mycorrhizae improves

864 photosynthesis and water status of Zea mays L. under drought stress. Plant, Soil and

865 Environment 58:186-191. DOI: 10.17221/23/2011-pse.

866 


\section{Figure 1}

Preferred Reporting Items for Systematic Reviews and Meta-analysis (PRISMA) flow diagram.

${ }^{1}$ We used the terms rain*fed or non-irrigat* and mycorrhiz* ${ }^{2}$ Web of science include 5 databases (Web of Science Core Collection, MEDLINE, SciELO Citation Index, KCl-Korean Journal Database and Russian Science Citation Index) ${ }^{3}$ We used the following inclusion criteria: (1) the articles had to be original research, (2) field studies under rainfed conditions, (3) involve an AMF treatment and a corresponding control and (4) contained replicated controlled trials.
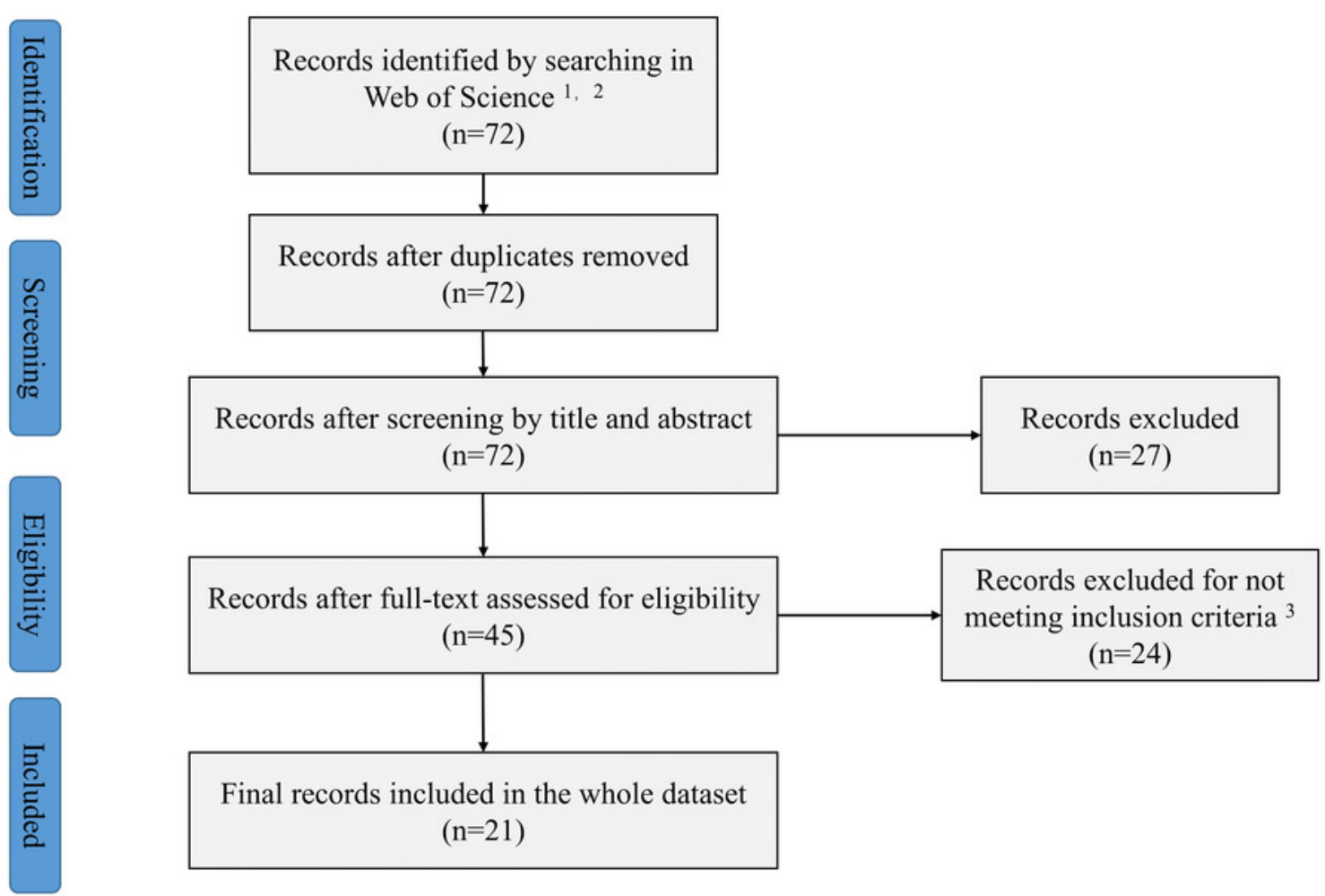
Figure 2

The locations of studies included in the Global Dataset of Arbuscular Mycorrhizal Fungi and Crop Yields under Rainfed Agroecosystem.

The black triangle represents the locations of studies.

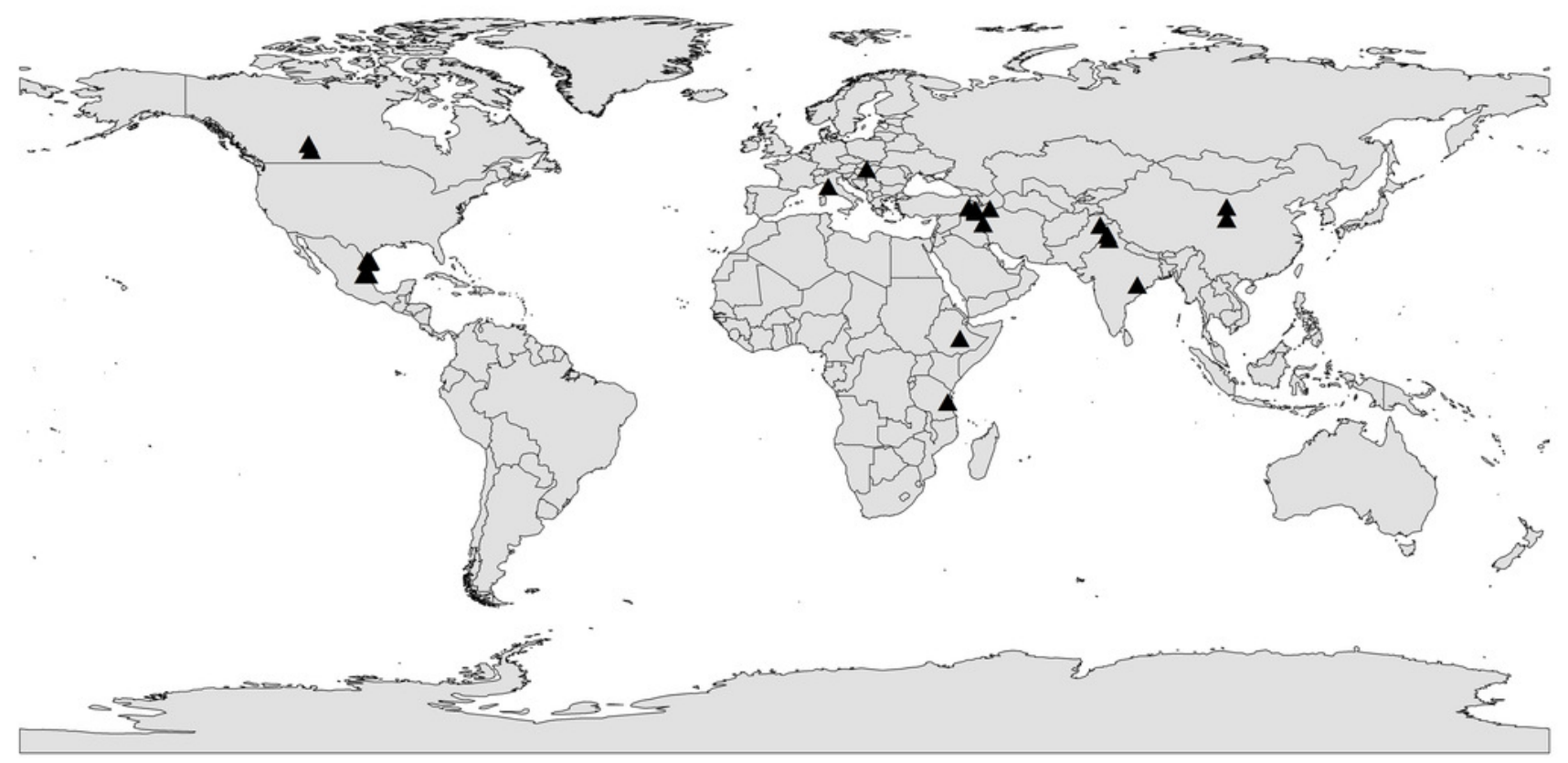




\section{Figure 3}

Effect of arbuscular mycorrhizal fungi (AMF) on crop yields under rainfed condition.

(a) Overall effect on crop yield in all, grain crops and non-grain crops. Effects are displayed as weighted means and $95 \%$ Cis. ' $n$ ' represents trial numbers and ' $L$ ' represents literature numbers. The vermilion square, blue triangle and yellow point represent the original data distribution of all, grain crops and non-grain crops. (b-d) Effect size for each trial in (b) all ( $\mathrm{Cl}=16 \%-30 \%)$, (c) grain crops ( $\mathrm{Cl}=14 \%-29 \%)$ and (d) non-grain crops $(\mathrm{Cl}=10 \%-60 \%)$. The vermilion, blue and yellow data point represent the positive, neutral and negative effect.

(a)
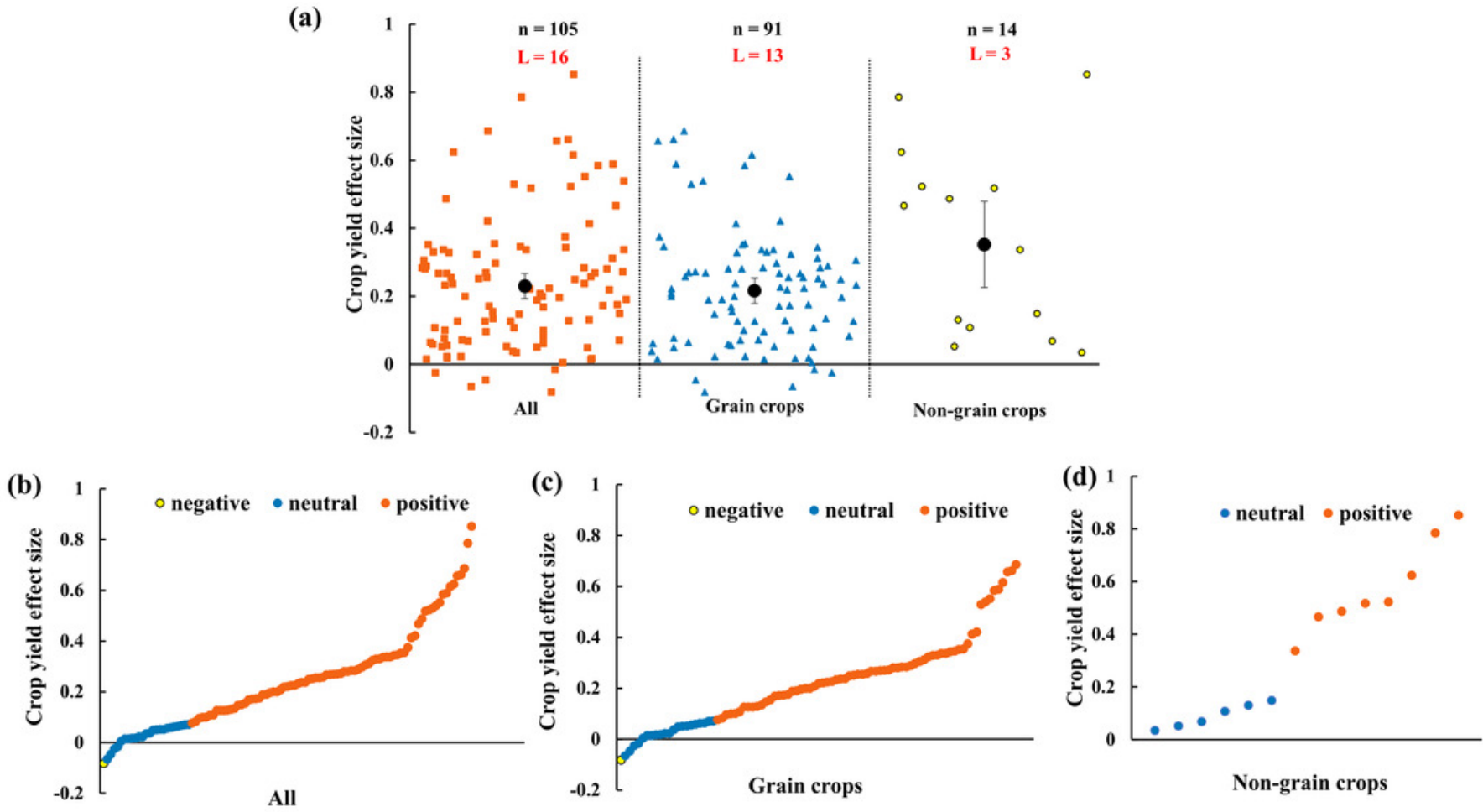
Figure 4

Effect of arbuscular mycorrhizal fungi (AMF) on crop yields under rainfed condition for crop functional group ( $\mathrm{N}$-fixing crops and non-N-fixing crops).

Effects are displayed as weighted means and 95\% Cis. ' $\mathrm{n}$ ' represents trial numbers and ' $\mathrm{L}$ ' represents literature numbers. The vermilion square and blue triangle represent the original data distribution of $\mathrm{N}$-fixing crops and non-N-fixing crops.

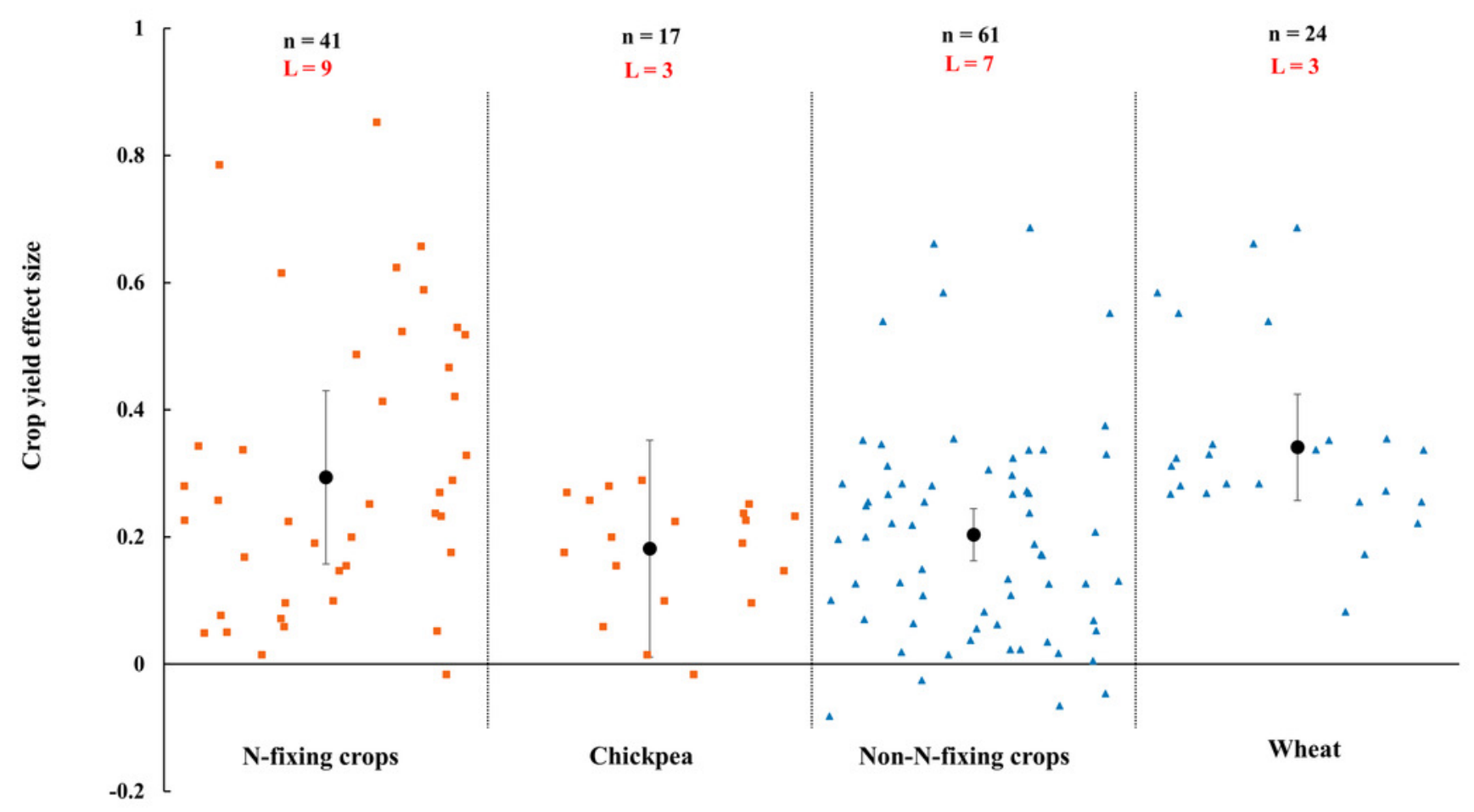




\section{Figure 5}

Impact of arbuscular mycorrhizal fungi (AMF) on crop yield component under rainfed condition (seed number per plant, pod/fruit number per plant, seed number per spike and thousand seed weight).

Effects are displayed as weighted means and 95\% Cis. ' $n$ ' represents trial numbers and ' $L$ ' represents literature numbers. The vermilion square, blue triangle, yellow point and reddish purple diamond represent the original data distribution of seed number per plant, pod/fruit number per plant, seed number per spike and thousand seed weight.

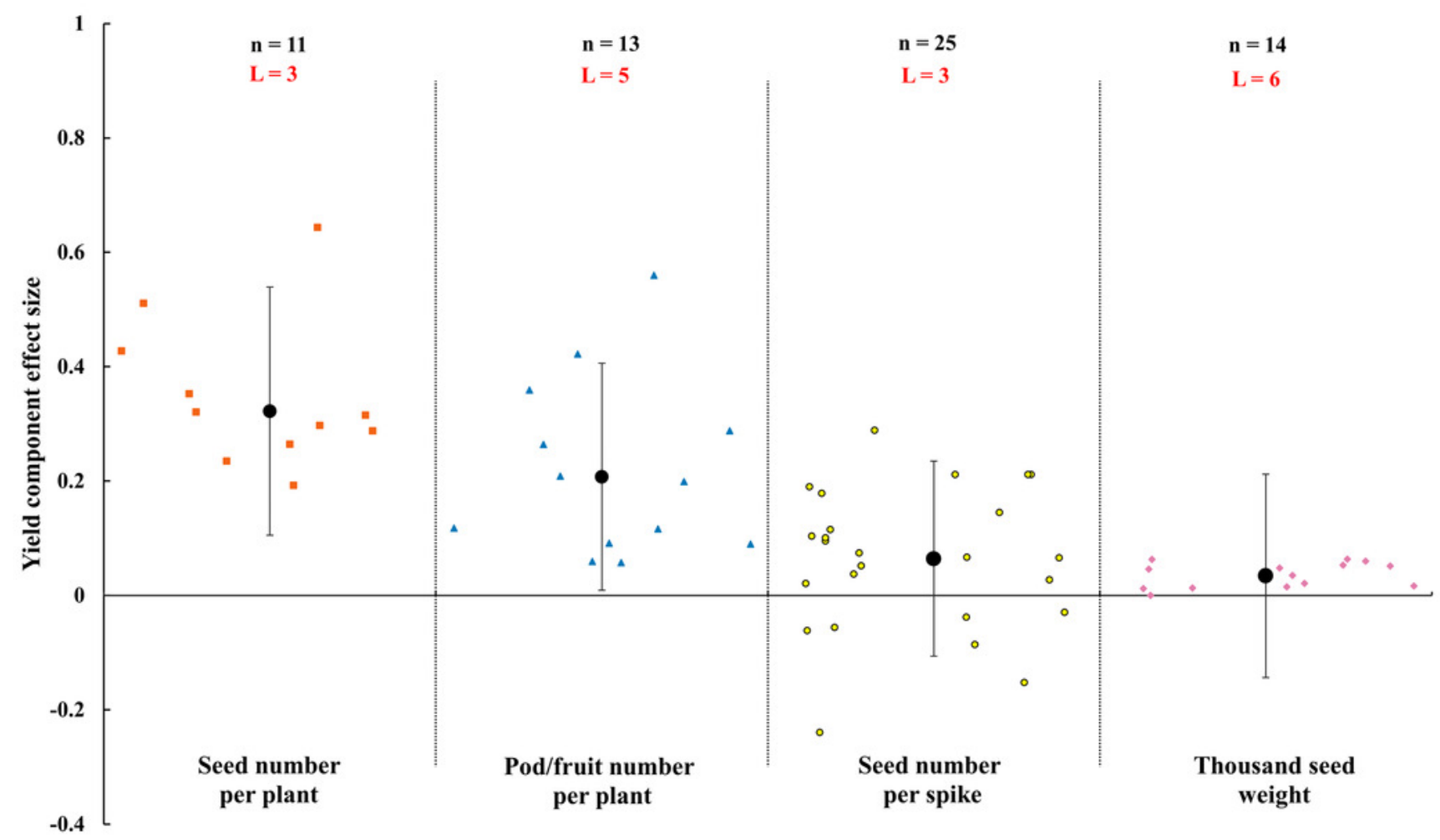




\section{Figure 6}

Effect of arbuscular mycorrhizal fungi (AMF) on shoot and root biomass under rainfed condition.

(a) Overall effect on biomass in all, grain crops and non-grain crops shoot biomass and all root biomass. Effects are displayed as weighted means and 95\% Cis. ' $n$ ' represents trial numbers and ' $\mathrm{L}$ ' represents literature numbers. The vermilion square, blue triangle and yellow point represent the original data distribution of all, grain crops and non-grain crops in shoot biomass. The reddish purple diamond represent the original data distribution of root biomass. (b-c) Effect size for each trial in (b) shoot biomass ( $\mathrm{Cl}=15 \%-33 \%)$, (c) root biomass $(\mathrm{Cl}=16 \%-43 \%)$. The vermilion and blue data point represent the positive and neutral effect.
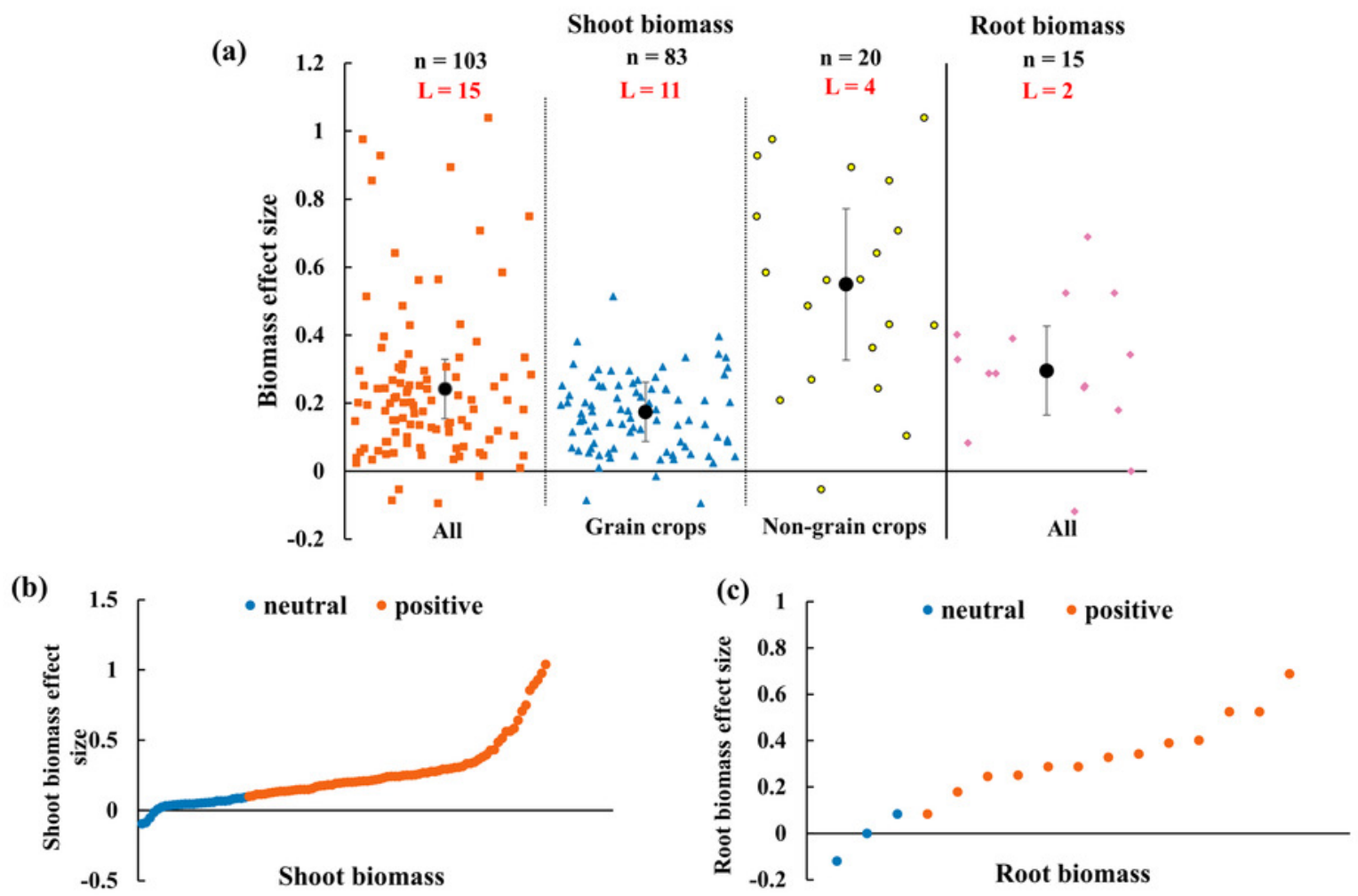
Figure 7

Effect of arbuscular mycorrhizal fungi (AMF) on shoot and root biomass between $\mathrm{N}$-fixing and non- $\mathrm{N}$-fixing crops under rainfed condition.

Effects are displayed as weighted means and 95\% Cis. ' $\mathrm{n}$ ' represents trial numbers and ' $\mathrm{L}$ ' represents literature numbers. The vermilion square and blue triangle represent the shoot biomass original data distribution of $\mathrm{N}$-fixing crops and non- $\mathrm{N}$-fixing crops. The yellow point and reddish purple diamond represent the root biomass original data distribution of $\mathrm{N}$-fixing crops and non-N-fixing crops.

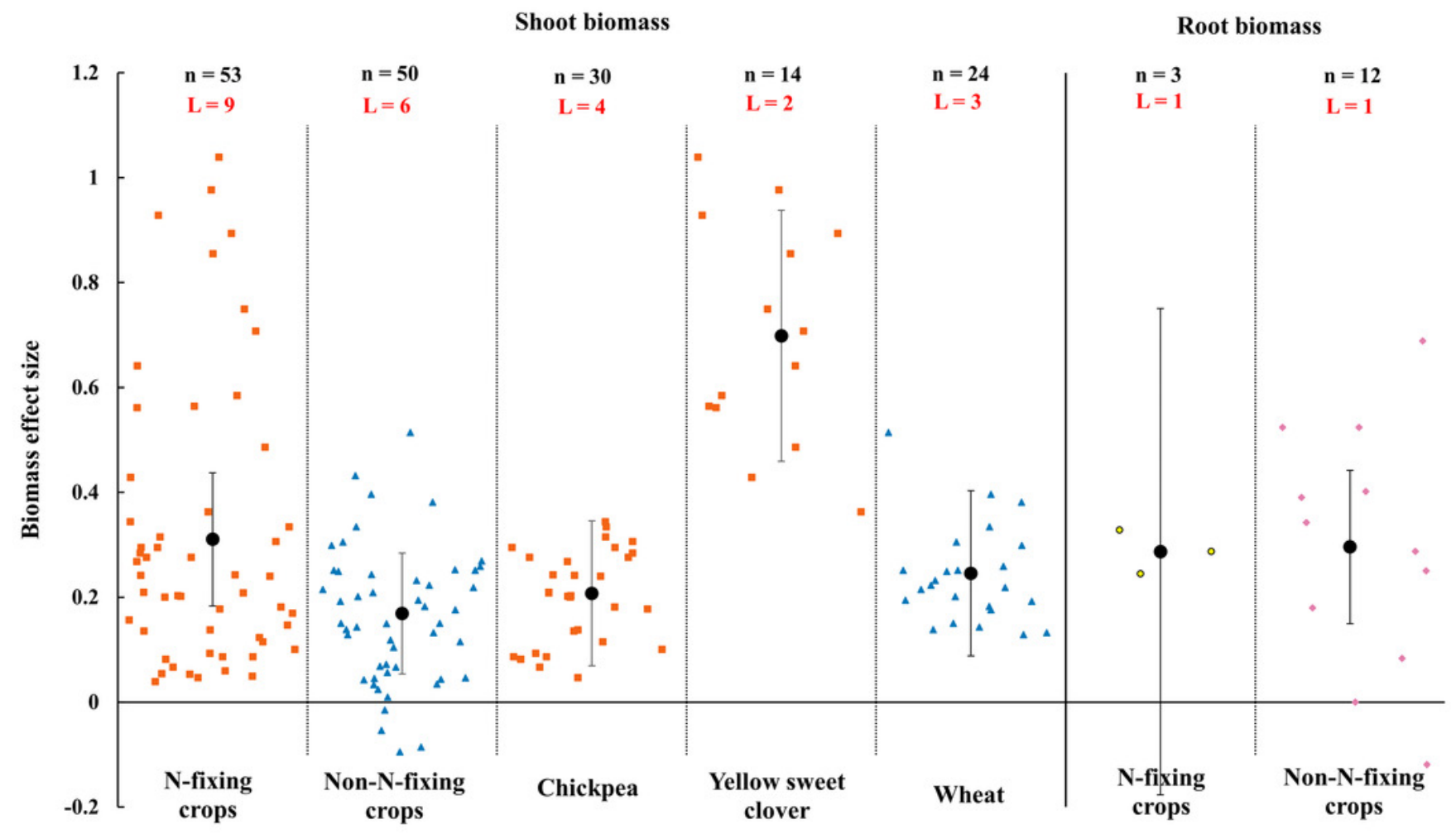


Figure 8

Effect of arbuscular mycorrhizal fungi (AMF) on plant proline and chlorophyll under rainfed condition.

Effects are displayed as weighted means and 95\% Cis. ' $n$ ' represents trial numbers and ' $L$ ' represents literature numbers. The vermilion square and blue triangle represent the original data distribution of proline and chlorophyll.

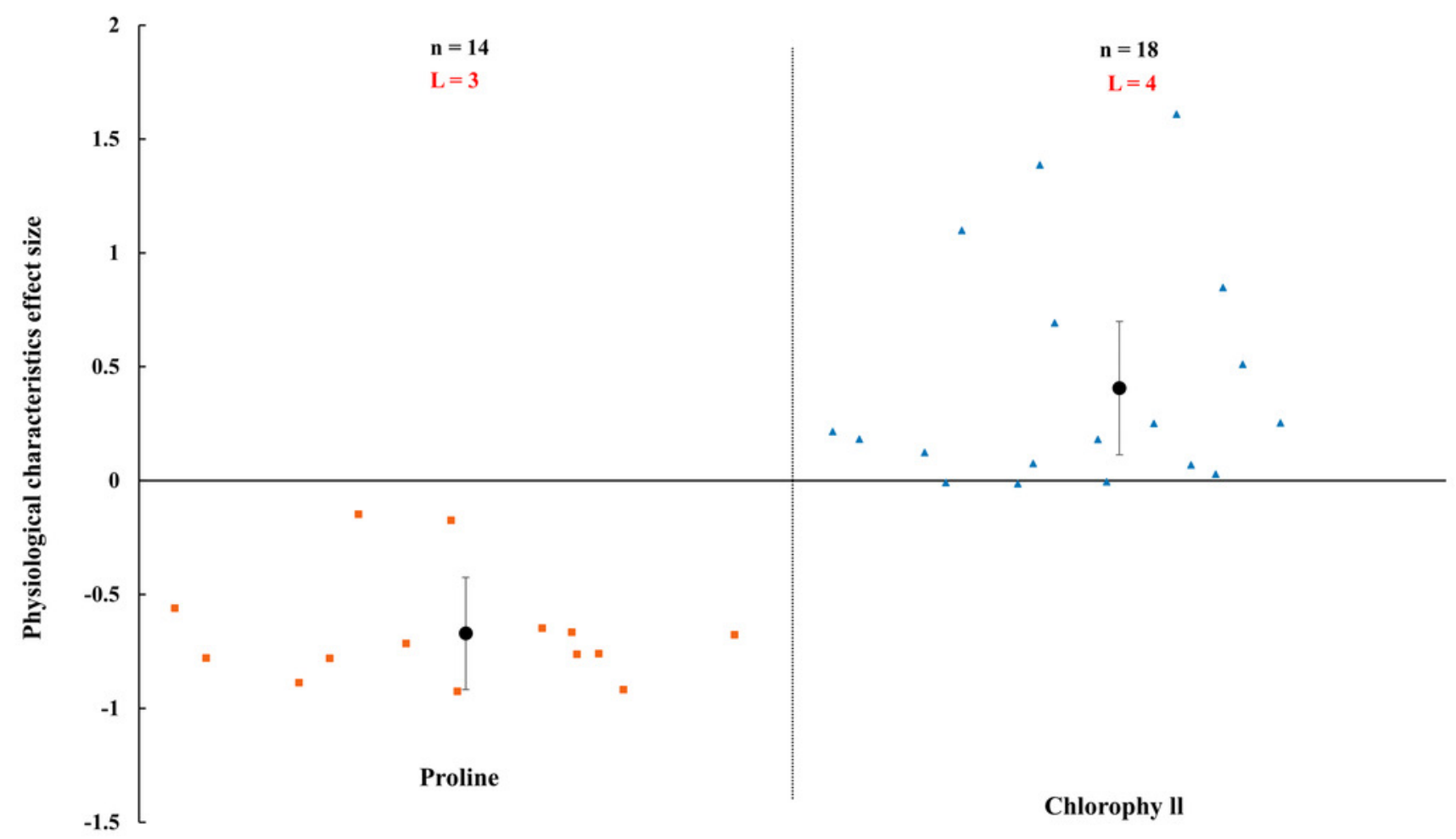


Figure 9

Effect of arbuscular mycorrhizal fungi (AMF) on nutrient concentration of shoot and leaf under rainfed condition.

Effects are displayed as weighted means and $95 \%$ Cis. ' $n$ ' represents trial numbers and ' $L$ ' represents literature numbers. The vermilion square and blue triangle represent the original data distribution of nitrogen and phosphorus concentration of shoot and leaf.

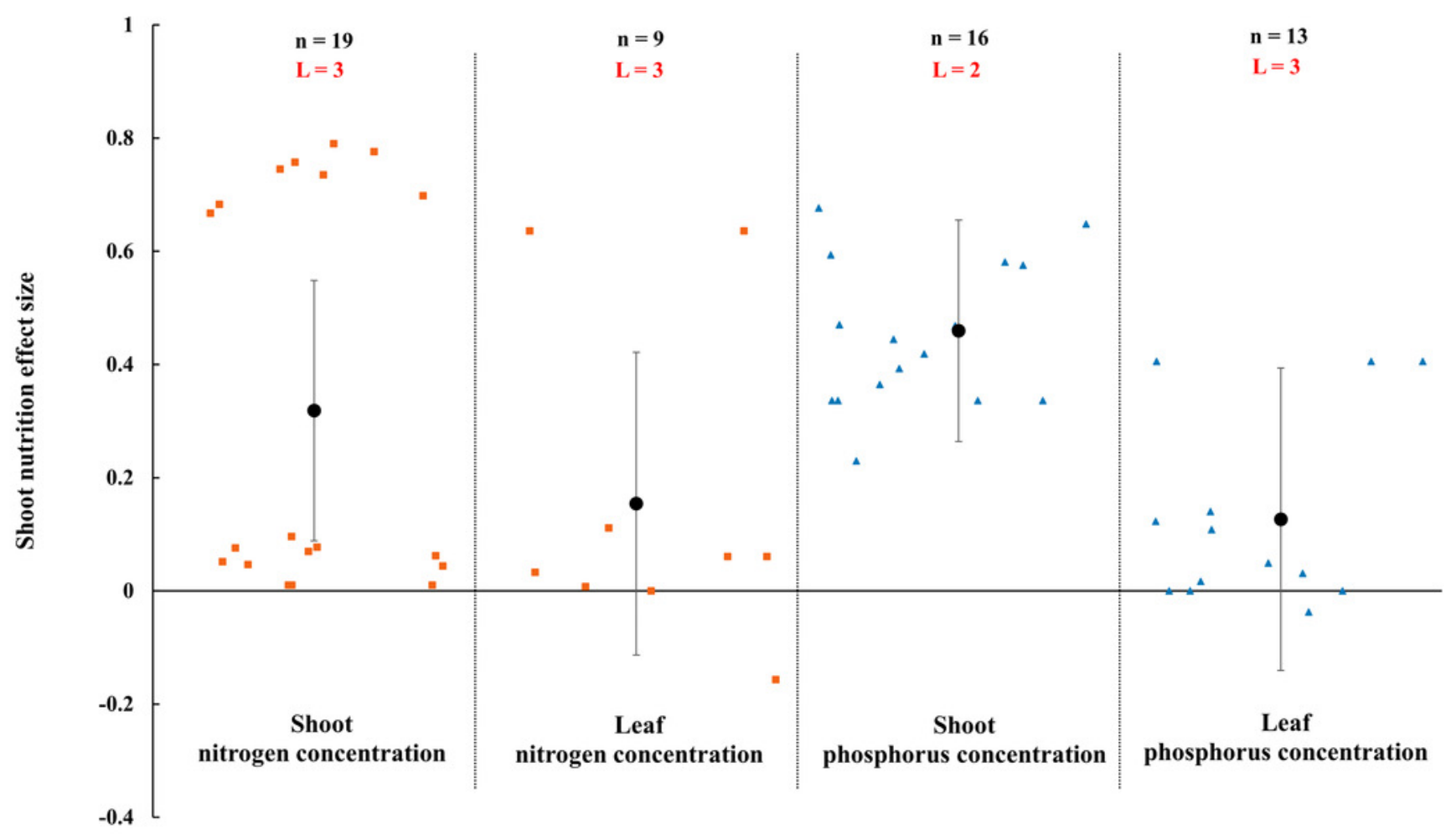




\section{Figure 10}

Effect of arbuscular mycorrhizal fungal (AMF) on nutrient concentration and uptake in seed under rainfed condition.

Effects are displayed as weighted means and $95 \%$ Cis. ' $\mathrm{n}$ ' represents trial numbers and ' $\mathrm{L}$ ' represents literature numbers. The vermilion square represents the original data distribution of phosphorus concentration and uptake of seed, the blue triangle represents the original data distribution of nitrogen concentration and uptake of seed.

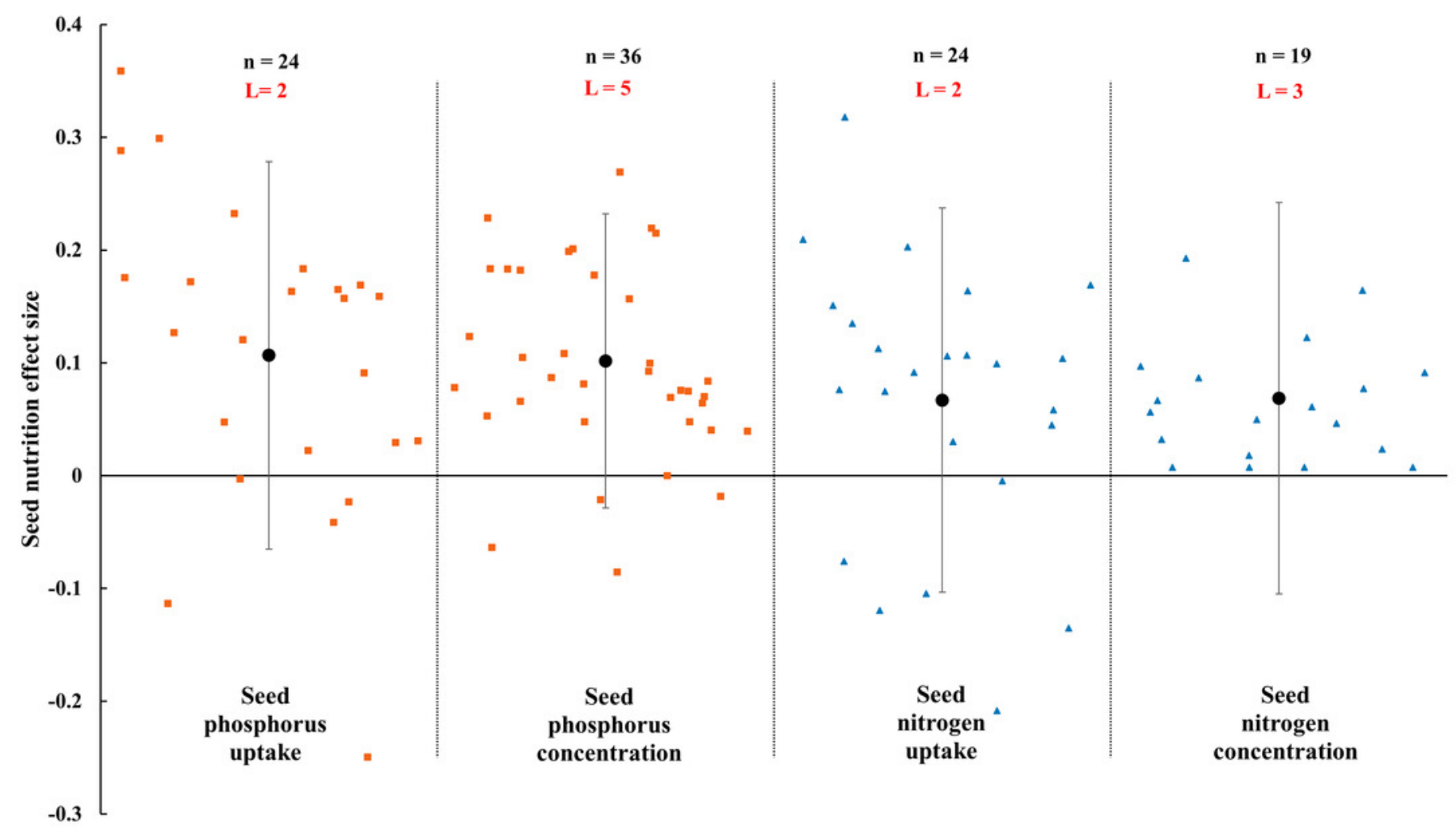




\section{Figure 11}

Structural equation model (SEM) analysis of relationships among AMF, response ratio of physiological characteristics (i.e., nutrition, chlorophyll and proline), biomass, yield component (i.e., pod/fruit number and harvest index) and yield.

Black solid arrows represent significant positive or negative effects. Black dashed arrows represent nonsignificant paths. Number near lines represent standardized path coefficients $(\mathrm{r})$, *** means $\mathrm{P}<0.001 ; * *$ means $\mathrm{P}<0.01 ; *$ means $\mathrm{P}<0.05$, respectively.

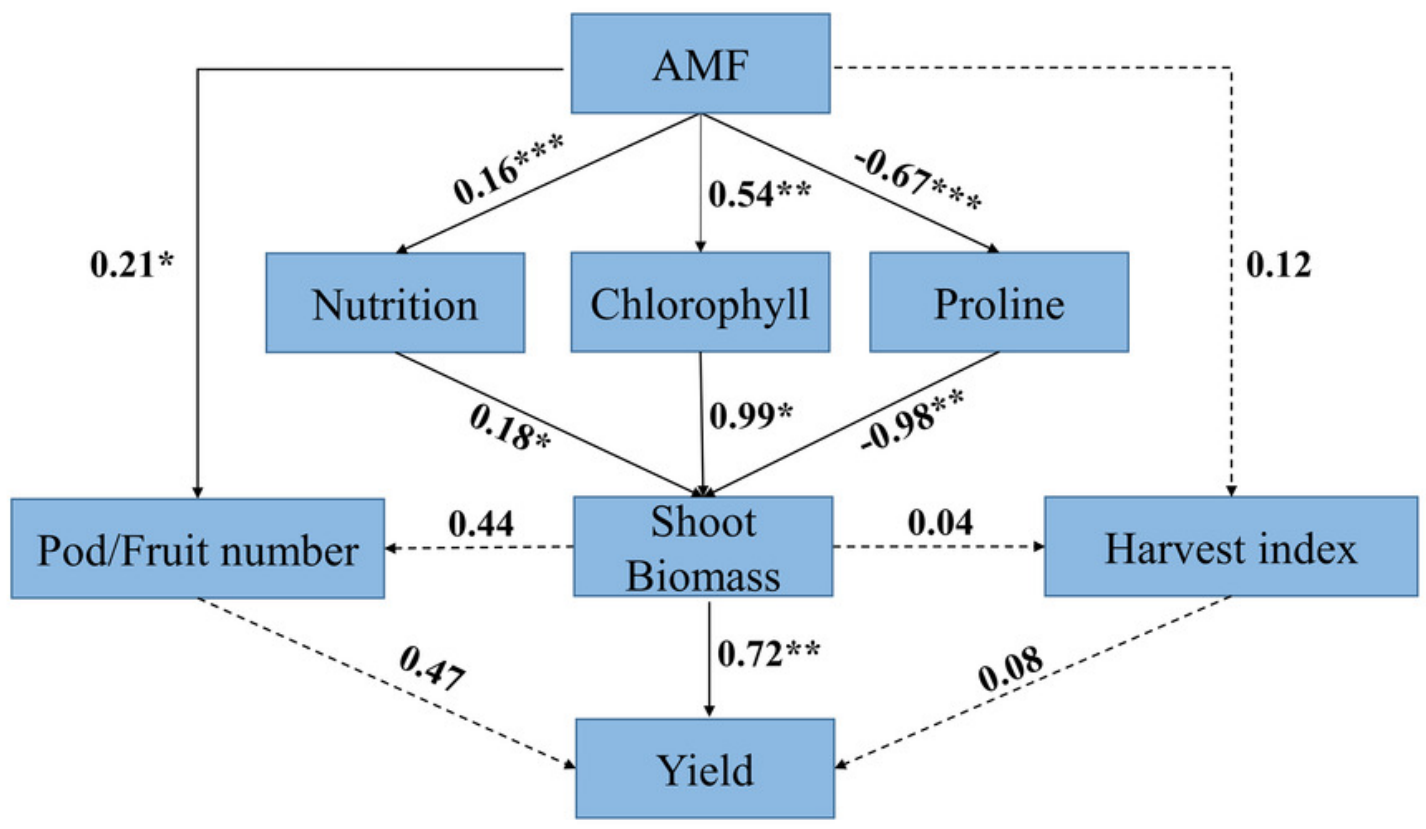

